INRA Prod. Anim.

2013, 26 (2), $77-100$

\title{
Le secteur laitier français à la croisée des chemins
}

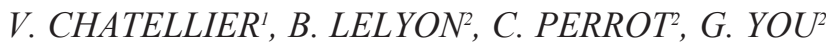 \\ ${ }^{1}$ INRA, UR1134 LERECO, F-44316 Nantes, France \\ 2 Institut de l'Elevage, Département Economie, F-75012 Paris, France \\ Courriel : vincent.chatellier@nantes.inra.fr
}

Trois décennies après son instauration, le régime des quotas laitiers sera abandonné à compter de 2015 au profit de la mise en œuvre d'un système de contractualisation entre les producteurs de lait et les industriels. Ce changement de cap est une évolution majeure, surtout en France où les quotas ont été utilisés pour répartir la production laitière sur le territoire, favoriser les exploitations de taille moyenne et encourager l'installation de jeunes agriculteurs. L'avenir du secteur laitier français s'inscrit dans un contexte caractérisé par une croissance soutenue de la demande mondiale de produits laitiers, une forte volatilité des prix, une concurrence intracommunautaire sérieuse, une augmentation du prix de certains intrants et un essor de nouvelles technologies susceptible d'influencer les rapports au travail et les gains de productivité.

La filière laitière française est dans une phase charnière de son histoire ou, en quelque sorte, à la croisée des chemins. Si cette filière est historiquement riche de la diversité de ses territoires, de ses produits et de ses modèles productifs (Pflimlin et al 2009), la préservation de cet acquis n'est pas certaine, d'autant plus qu'une modification substantielle du cadre concurrentiel est clairement amorcée. Les stratégies déployées par les pouvoirs publics et les parties prenantes de la filière seront déterminantes quant aux évolutions à venir.

Dans la continuité de décisions politiques prises lors des précédentes réformes de la Politique Agricole Commune (PAC), les propositions législatives faites en octobre 2011 par la Commission européenne confirment la fin du régime des quotas laitiers à l'horizon 2015 (Commission européenne 2011a). Cette rupture dans le mode de régulation de l'offre est majeure, surtout en France où les pouvoirs publics ont toujours cherché, au travers des modalités de gestion des quotas, à contenir le mouvement de concentration géographique de la production et à favoriser le développement d'exploitations familiales de taille moyenne (Barthélémy et David 1999). Sans revenir ici sur les débats controversés qui existent entre experts sur le bien-fondé ou non du régime des quotas laitiers (Guyomard et Mahé 1993, Gouin 2005, Kroll et al 2010a, Pflimlin 2010), cette évolution traduit le passage d'une régu- lation publique du secteur à une régulation privée, ce par le développement de relations contractuelles entre producteurs et industriels. Elle s'inscrit dans la même veine que celle qui prévaut depuis plusieurs années au sein de la PAC, à savoir un désengagement de la puissance publique dans l'orientation des productions agricoles, avec la diminution des restitutions aux exportations, la suppression des aides à l'incorporation de produits laitiers dans l'industrie agro-alimentaire et le recours moins fréquent au stockage public et privé.

Le développement de la filière laitière française s'inscrit aujourd'hui dans un cadre économique en mouvement, comme en témoignent, par exemple, les cinq points qui suivent $: i$ ) l'internationalisation croissante des marchés agricoles, encouragée par les règles multilatérales arrêtées dans le cadre de l'Organisation Mondiale du Commerce (OMC), stimule les échanges et fait apparaître progressivement de nouveaux acteurs (montée en puissance des Etats-Unis dans les exportations mondiales de produits laitiers, augmentation des importations chinoises et russes...) ; ii) si la demande mondiale de produits laitiers est croissante et relève de plus en plus des pays en développement, la consommation française est, quant à elle, plutôt stable (voire légèrement déclinante); iii) la forte volatilité du prix de vente des produits laitiers et du prix des intrants modifie les conditions de la rentabilité des élevages et interroge sur les modèles techniques qui seront économiquement les plus robustes à long terme; iv) le taux de restructuration des exploitations laitières françaises, plus élevé que dans la plupart des autres orientations de production, ne faiblit pas, alors même que de nouvelles technologies de traite permettent d'envisager de futurs accroissements des gains de productivité ; $v$ ) le maintien de la production laitière dans les zones de polyculture-élevage à faible densité laitière est d'autant plus délicat que la tentation est grande pour les producteurs de se reconvertir en céréales (prix favorables et moindres astreintes de travail). Dans ce contexte, l'objectif est ici de proposer une analyse de la situation actuelle du secteur laitier français à la veille de la suppression des quotas. Trois parties seront distinguées dans cet article :

- La première présente les principales grandes tendances de l'évolution récente du secteur laitier français en distinguant successivement la consommation de produits laitiers, la production et l'utilisation du lait, les acteurs industriels de la transformation, les échanges et les prix.

- La deuxième porte sur les exploitations laitières et la diversité des modèles régionaux de production. Après avoir mis en lumière les principaux facteurs de différenciation des modèles productifs existants, elle souligne les écarts importants de productivité du travail et de résultats économiques 
entre les différents bassins de production français.

- La troisième discute des mesures transitoires adoptées, à l'échelle communautaire et nationale, pour préparer l'échéance de 2015 et aborde la question des stratégies susceptibles d'être déployées par les industriels français pour encadrer l'offre de lait. Elle revient ensuite sur quelques enjeux plus globaux de la fin des quotas laitiers.

\section{1 / La place de la France dans la dynamique des marchés laitiers}

L'objectif de cette première partie est de dresser un diagnostic sur l'évolution récente de la situation du secteur laitier français (en termes de production, de consommation, d'échanges et de prix), en écartant à ce stade la question de la diversité des exploitations et des territoires concernés qui sera traitée dans la deuxième partie. Si la production laitière française a légèrement baissé depuis l'application des quotas laitiers en 1984, ce secteur est devenu davantage exportateur, dans un contexte où le niveau de consommation national plafonne, en dépit d'une palette extraordinairement diversifiée de produits laitiers. Les acteurs industriels de la transformation se concentrent pour optimiser leurs coûts de production et la volatilité accentuée des prix conduit les agriculteurs à s'interroger sur les systèmes techniques à privilégier pour aborder l'avenir.

\section{1 / La consommation de pro- duits laitiers}

Avec $0,9 \%$ de la population mondiale en 2010, la France contribue pour environ $3 \%$ à la consommation mondiale de lait et de produits laitiers. Les Français sont parmi les plus gros consommateurs de produits laitiers au monde, avec une consommation individuelle plus de trois fois supérieure à la moyenne mondiale (105 kg en équivalent lait par habitant et par an, toutes catégories de lait confondues). Après une période de croissance assez soutenue (entre 1960 et 1990), la consommation individuelle de produits laitiers tend à légèrement diminuer en France (de l'ordre de 7\% entre 1995 et 2012); l'essor démographique (+9\% sur la même période) contribuant cependant à maintenir le niveau global de la demande. Une analyse déclinée selon les catégories de produits laitiers permet de mieux comprendre les évolutions en cours.

Le lait liquide. Les Français en consomment modérément (66 kg par an en 2010) comparativement aux Irlandais $(135 \mathrm{~kg})$, Finlandais (127 kg), Britanniques (107 kg),
Australiens (105 kg) et Nord-Américains $(79 \mathrm{~kg})$. Avec un niveau de consommation comparable aux Brésiliens, ils devancent les Mexicains, $(40 \mathrm{~kg})$, les Indiens $(40 \mathrm{~kg})$, les Japonais $(32 \mathrm{~kg})$ et les Chinois $(10 \mathrm{~kg})$. En France, le lait liquide est consommé à $95 \%$ sous la forme de lait longue conservation (technologie dite « Ultra Haute Température »), produit hyperconcurrentiel, alors que la consommation de lait frais est dominante dans la plupart des pays de l'Europe du Nord. Les fabrications françaises de laits liquides conditionnés répondant aux normes de l'agriculture biologique $(1,2 \%$ de la collecte du lait de vache) ont progressé pour atteindre $5 \%$ des parts de marché (Le Tollec 2012). Face à la baisse de la consommation de laits liquides (basiques), évolution qui doit être reliée aux tendances de transformation du modèle alimentaire français (Laisney 2011), un essor de la consommation de laits spécifiques (laits aromatisés, vitaminés, de croissance...) est observé

Les produits laitiers ultra-frais. Le marché français des ultra-frais (yaourts et laits fermentés, fromages frais, desserts lactés) a progressé jusqu'en 2007 pour stagner ensuite aux alentours de $38 \mathrm{~kg}$ par habitant et par an (dont $21 \mathrm{~kg}$ de yaourts en 2010 , soit $+20 \%$ en dix ans).

Le beurre. Avec $7,9 \mathrm{~kg}$ de beurre consommés par an, les Français occupent le premier rang à l'échelle internationale, loin devant les Indiens $(3,5 \mathrm{~kg}$, consommés essentiellement sous la forme de " ghee », un beurre clarifié qui se conserve mieux), les Nord-Américains $(2,2 \mathrm{~kg})$, les Russes $(2,2 \mathrm{~kg})$, les Japonais $(0,6 \mathrm{~kg})$ et les Chinois $(0,1 \mathrm{~kg})$. Si les achats des ménages français en beurre ont baissé (- $30 \%$ en 15 ans), l'utilisation de beurre par l'industrie agro-alimentaire progresse, de même que certains segments spécifiques (beurre allégé, beurre haut de gamme...). Les achats des ménages en crèmes de consommation (UHT, fraîche, allégée ou non, épaisse...) connaissent, quant à eux, une croissance particulièrement soutenue $(+25 \%$ en quinze ans).

Les fromages. Avec $25 \mathrm{~kg}$ de fromages consommés par habitant et par an, la France occupe le deuxième rang communautaire derrière la Grèce $(31 \mathrm{~kg}$, dont une part importante de feta). La consommation est insignifiante en Chine et en Inde et atteint $15 \mathrm{~kg}$ aux EtatsUnis où la consommation augmente du fait de l'essor des utilisations de mozzarella. En France, pays où la diversité de l'offre est extraordinaire avec 350 à 400 types de fromages, la consommation individuelle a progressé de manière soutenue entre 1980 et 2000 , puis elle s'est ensuite stabilisée. Les fromages à pâtes pressées cuites bénéficient d'une hausse de la demande alors que les fromages à pâtes molles connaissent un léger déclin ; ceux à pâtes persillées et non cuites stagnent (Institut de l'Elevage 2012b).

Les Français sont aujourd'hui de grands consommateurs de produits laitiers, y compris de manière indirecte par les utilisations qui sont faites des matières grasse et protéique d'origine laitière par les industries agroalimentaires (FranceAgriMer 2012). Du fait de ce niveau déjà élevé de consommation et de la faible croissance démographique, les Français ne sont pas amenés à jouer un rôle significatif dans l'évolution attendue de la demande mondiale. D'après les estimations de l'Organisation de Coopération et de Développement Economique (OCDE) et de l'organisation des Nations Unies pour l'alimentation et l'agriculture (FAO), la consommation mondiale de produits laitiers devrait progresser de $22 \%$ entre 2010 et 2021 (OCDE-FAO 2012). Les pays en développement, notamment ceux de l'Asie (Inde et Chine), qui représentent une part déjà élevée de la consommation totale, vont être les principaux moteurs de cette croissance (tableau 1). Plusieurs facteurs y contribuent: la croissance démographique ; l'amélioration du revenu moyen des ménages et l'occidentalisation croissante des régimes alimentaires ; le développement interne de l'offre et l'essor des technologies (conditionnement des produits, méthode de conservation...) ; l'amélioration de la logistique (transport et acheminement des produits) et des réseaux de distribution. Les Pays les Moins Avancés (PMA, selon la nomenclature de l'Organisation des Nations Unies) occuperont, quant à eux, une place très modeste dans ces évolutions.

D'après les travaux de la Direction Générale de l'Agriculture et du Développement Rural (DGAGRI) de la Commission européenne (Commission européenne 2012a), la consommation européenne globale devrait progresser plus modestement que dans de nombreux pays en développement : $+4 \%$ pour les fromages entre 2012 et $2022 ;+4 \%$ pour le beurre $;+3 \%$ pour la poudre de lait entier ; $+1 \%$ pour la poudre de lait écrémé. Ces analyses montrent que ni la France, ni l'Europe, ne seront véritablement au cœur de la dynamique de croissance. La tonicité de la demande internationale pourrait être bénéfique à long terme pour le commerce français, en fonction cependant de l'évolution des jeux concurrentiels entre les principaux fournisseurs du marché mondial (Nouvelle-Zélande, UE et Etats-Unis) et de la capacité des pays asiatiques à 
Tableau 1. Le poids des zones géographiques dans la consommation mondiale de produits laitiers en 2010 et l'estimation du poids des zones dans l'évolution de la consommation attendue entre 2010 et 2021.

Source : FAO-OCDE.

\begin{tabular}{|c|c|c|c|c|c|c|c|c|c|c|}
\hline & \multicolumn{2}{|c|}{$\begin{array}{c}\text { Lait liquide et } \\
\text { produits frais (\%) }\end{array}$} & \multicolumn{2}{|c|}{ Beurre (\%) } & \multicolumn{2}{|c|}{ Fromages $(\%)$} & \multicolumn{2}{|c|}{$\begin{array}{l}\text { Poudre de lait } \\
\text { écrémé }(\%)\end{array}$} & \multicolumn{2}{|c|}{$\begin{array}{c}\text { Poudre } \\
\text { de lait entier (\%) }\end{array}$} \\
\hline & 2010 & $\begin{array}{c}\text { Var. } \\
2010-21 \\
\end{array}$ & 2010 & $\begin{array}{c}\text { Var. } \\
2010-21 \\
\end{array}$ & 2010 & $\begin{array}{c}\text { Var. } \\
2010-21 \\
\end{array}$ & 2010 & $\begin{array}{c}\text { Var. } \\
2010-21 \\
\end{array}$ & 2010 & $\begin{array}{c}\text { Var. } \\
2010-21 \\
\end{array}$ \\
\hline Monde & 100,0 & 100,0 & 100,0 & 100,0 & 100,0 & 100,0 & 100,0 & 100,0 & 100,0 & 100,0 \\
\hline Pays développés & 31,5 & 11,4 & 36,2 & 10,5 & 77,1 & 62,7 & 48,4 & 19,6 & 14,1 & 7,4 \\
\hline $\begin{array}{l}\text { Pays en } \\
\text { développement }\end{array}$ & 68,5 & 88,6 & 63,8 & 89,5 & 22,9 & 37,3 & 51,6 & 80,4 & 85,9 & 92,6 \\
\hline Pays Moins Avancés & 6,1 & 9,4 & 1,8 & 3,1 & 1,8 & 3,3 & 2,9 & 4,5 & 5,2 & 8,0 \\
\hline Union européenne-27 & 10,6 & 2,0 & 19,4 & 0,6 & 40,6 & 22,2 & 18,1 & $-0,8$ & 7,2 & 2,8 \\
\hline Inde & 26,5 & 41,1 & 41,8 & 63,8 & 0,0 & 0,0 & 5,8 & 4,7 & 0,2 & 0,6 \\
\hline États-Unis & 5,8 & 0,3 & 6,7 & 6,8 & 23,2 & 31,7 & 13,2 & 14,5 & 0,4 & 0,2 \\
\hline Chine & 7,7 & 11,8 & 1,3 & 1,7 & 1,6 & 3,1 & 4,3 & 9,5 & 29,9 & 34,0 \\
\hline Afrique & 7,5 & 8,7 & 3,9 & 4,9 & 4,6 & 7,3 & 7,1 & 17,4 & 14,5 & 7,3 \\
\hline Brésil & 3,1 & 3,1 & 0,7 & 0,7 & 3,3 & 4,3 & 4,1 & 6,1 & 12,0 & 12,4 \\
\hline Nouvelle-Zélande & 0,1 & 0,0 & 0,3 & 0,0 & 0,1 & 0,1 & 1,1 & 0,0 & 0,1 & 0,1 \\
\hline Argentine & 0,4 & 0,3 & 0,3 & $-0,1$ & 2,4 & 1,6 & 0,5 & 0,4 & 1,4 & $-2,7$ \\
\hline Mexique & 1,1 & 1,3 & 0,4 & 0,1 & 1,2 & 1,2 & 4,8 & 4,9 & 4,7 & 4,3 \\
\hline Australie & 0,5 & 0,3 & 0,7 & 0,5 & 1,2 & 0,9 & 1,6 & 0,9 & 1,0 & 1,4 \\
\hline Canada & 0,6 & 0,1 & 0,9 & $-0,2$ & 2,0 & 0,2 & 2,2 & $-0,7$ & 0,3 & 0,1 \\
\hline Japon & 1,0 & $-0,1$ & 0,8 & $-0,5$ & 1,2 & 1,4 & 5,4 & $-0,9$ & 0,3 & $-0,1$ \\
\hline Autres pays & 35,0 & 31,1 & 22,8 & 21,8 & 18,5 & 26,1 & 31,7 & 43,9 & 28,1 & 39,6 \\
\hline
\end{tabular}

Tableau 2. Le poids des zones géographiques dans la production mondiale de lait en 2000 et 2010 et l'estimation du poids des zones dans l'évolution de la production attendue entre 2010 et 2021.

Source : FAO-OCDE.

\begin{tabular}{|c|c|c|c|c|c|c|c|}
\hline & \multicolumn{2}{|c|}{2000} & \multicolumn{2}{|c|}{2010} & \multicolumn{2}{|c|}{ Estimations 2021} & \multirow{2}{*}{$\begin{array}{c}\text { Croissance } \\
\text { Mondiale } \\
2010-2021\end{array}$} \\
\hline & $\begin{array}{r}\text { Milliards } \\
\text { de litres }\end{array}$ & $\begin{array}{c}\% \text { du total } \\
\text { mondial }\end{array}$ & $\begin{array}{l}\text { Milliards } \\
\text { de litres }\end{array}$ & $\begin{array}{c}\% \text { du total } \\
\text { mondial }\end{array}$ & $\begin{array}{r}\text { Milliards } \\
\text { de litres }\end{array}$ & $\begin{array}{c}\% \text { du total } \\
\text { mondial }\end{array}$ & \\
\hline Monde & 576 & 100,0 & 710 & 100,0 & 880 & 100,0 & 100,0 \\
\hline Pays développés & 341 & 59,3 & 362 & 51,0 & 411 & 46,7 & 29,2 \\
\hline $\begin{array}{l}\text { Pays en } \\
\text { développement }\end{array}$ & 234 & 40,7 & 348 & 49,0 & 469 & 53,3 & 70,8 \\
\hline $\begin{array}{l}\text { Pays moins avancés } \\
\text { (PMA) }\end{array}$ & 20 & 3,4 & 27 & 3,8 & 39 & 4,4 & 6,7 \\
\hline Union européenne-27 & 150 & 26,0 & 149 & 20,9 & 158 & 17,9 & 5,3 \\
\hline Inde & 80 & 13,8 & 117 & 16,4 & 166 & 18,8 & 28,7 \\
\hline États-Unis & 76 & 13,2 & 87 & 12,3 & 103 & 11,7 & 9,3 \\
\hline Chine & 12 & 2,1 & 43 & 6,1 & 60 & 6,9 & 10,1 \\
\hline Afrique & 25 & 4,3 & 36 & 5,1 & 47 & 5,4 & 6,6 \\
\hline Brésil & 23 & 4,1 & 31 & 4,4 & 38 & 4,4 & 4,1 \\
\hline Nouvelle-Zélande & 12 & 2,1 & 17 & 2,4 & 24 & 2,8 & 4,2 \\
\hline Argentine & 10 & 1,7 & 10 & 1,5 & 17 & 1,9 & 3,8 \\
\hline Mexique & 10 & 1,7 & 11 & 1,6 & 12 & 1,3 & 0,4 \\
\hline Australie & 11 & 1,9 & 9 & 1,3 & 11 & 1,2 & 0,8 \\
\hline Canada & 8 & 1,4 & 8 & 1,2 & 9 & 1,0 & 0,3 \\
\hline Japon & 8 & 1,5 & 8 & 1,1 & 7 & 0,8 & $-0,2$ \\
\hline Autres pays & 151 & 26,2 & 183 & 25,8 & 228 & 25,9 & 26,5 \\
\hline
\end{tabular}


satisfaire la demande domestique par l'essor de leur propre production.

\section{2 / La production laitière et l'utilisation de la collecte}

La contribution française et européenne à l'offre mondiale de lait est décroissante et cette tendance devrait persister. Ainsi, d'après les estimations de la FAO et de l'OCDE, l'UE-27 devrait représenter $18 \%$ de la production laitière mondiale en 2021 contre $26 \%$ en 2000 (tableau 2). A cette échéance, les pays en développement assureront un peu plus de la moitié de la production laitière mondiale. Avec $18 \%$ de l'offre, l'Inde jouera un rôle encore plus important qu'au début de la décennie et devancera les Etats-Unis, la Chine, l'Afrique, la Russie et le Brésil. L'Océanie (Nouvelle-Zélande et Australie) représentera moins de $4 \%$ de l'offre mondiale, soit une contribution marginale au regard de sa participation au commerce.

La France assure 3,4\% de la production laitière mondiale et $16,1 \%$ de la production laitière européenne. Elle occupe le second rang des pays européens derrière l'Allemagne et devance, par ordre décroissant, le RoyaumeUni, la Pologne, les Pays-Bas, l'Italie et l'Espagne (tableau 3). La collecte française de lait s'est élevée à 23,9 milliards de litres en 2011 pour un cheptel moyen de 3,7 millions de vaches laitières (soit un rendement laitier de $6500 \mathrm{~kg}$ de lait en moyenne par vache et par an). Depuis la mise en ouvre des quotas en 1984, les livraisons françaises de lait de vache ont baissé de $6 \%$ alors que le cheptel de vaches laitières a connu un recul plus drastique de $48 \%$ du fait de l'amélioration de la productivité des animaux.

En France, les volumes de lait collectés ne sont pas stables d'un mois à l'autre, comme cela est vérifié, avec des amplitudes au demeurant beaucoup plus fortes, dans de nombreux autres pays tels que 1'Irlande et la Nouvelle-Zélande. La saisonnalité est caractérisée par un pic de production en mars-avril et un creux de production en été. Ces variations, qui tiennent pour partie aux modèles techniques privilégiés (dates de vêlage...), ont des répercussions importantes tant sur la valorisation commerciale des produits, avec le développement de produits industriels à faible rentabilité lorsque les débouchés sont insuffisants, que sur l'organisation du travail dans les entreprises pour adapter le potentiel de maind'œuvre aux flux variables de la collecte.

Tableau 3. La production laitière, le cheptel, le rendement laitier et le prix du lait dans l'UE-27. Classement des pays par ordre décroissant du volume de production laitière.

Source : Commission européenne.

\begin{tabular}{|c|c|c|c|c|c|c|}
\hline & \multicolumn{2}{|c|}{$\begin{array}{l}\text { Production de lait de } \\
\text { vaches (2010) }\end{array}$} & \multirow{2}{*}{$\begin{array}{l}\text { Collecte en \% } \\
\text { de la production } \\
\text { de lait (2010) }\end{array}$} & \multirow{2}{*}{$\begin{array}{c}\text { Effectif de } \\
\text { vaches laitières } \\
\text { (en milliers, 2011) }\end{array}$} & \multirow{2}{*}{$\begin{array}{c}\text { Rendement par } \\
\text { vache } \\
\text { (kg par an, 2010) }\end{array}$} & \multirow{2}{*}{$\begin{array}{c}\text { Prix du lait } \\
\text { de vache payé } \\
\text { (euros/t) } \\
\text { Moyenne 2009-11 }\end{array}$} \\
\hline & $\begin{array}{l}\text { Millions } \\
\text { de litres }\end{array}$ & $\begin{array}{c}\% \text { de } \\
\text { I'UE-27 }\end{array}$ & & & & \\
\hline Allemagne & 29594 & 19,8 & 98 & 4182 & 7077 & 307 \\
\hline France & 24000 & 16,1 & 98 & 3641 & 6592 & 323 \\
\hline Royaume-Uni & 13960 & 9,4 & 97 & 1847 & 7558 & 290 \\
\hline Pologne & 12279 & 8,2 & 73 & 2529 & 4855 & 271 \\
\hline Pays-Bas & 11941 & 8,0 & 97 & 1518 & 7866 & 327 \\
\hline Italie & 11364 & 7,6 & 92 & 1746 & 6050 & 353 \\
\hline Espagne & 6357 & 4,3 & 92 & 845 & 7521 & 308 \\
\hline Irlande & 5350 & 3,6 & 100 & 1027 & 5209 & 309 \\
\hline Danemark & 4910 & 3,3 & 98 & 573 & 8569 & 327 \\
\hline Roumanie & 4500 & 3,0 & 20 & 1179 & 3818 & 249 \\
\hline Autriche & 3258 & 2,2 & 85 & 533 & 6115 & 330 \\
\hline Belgique & 3111 & 2,1 & 99 & 518 & 6009 & 300 \\
\hline Suède & 2862 & 1,9 & 100 & 349 & 8211 & 335 \\
\hline R. tchèque & 2683 & 1,8 & 86 & 375 & 7146 & 287 \\
\hline Finlande & 2336 & 1,6 & 98 & 284 & 8218 & 417 \\
\hline Portugal & 1957 & 1,3 & 93 & 243 & 8045 & 305 \\
\hline Lituanie & 1733 & 1,2 & 74 & 360 & 4815 & 248 \\
\hline Hongrie & 1685 & 1,1 & 78 & 239 & 7050 & 269 \\
\hline Bulgarie & 1124 & 0,8 & 50 & 292 & 3855 & 294 \\
\hline Slovaquie & 918 & 0,6 & 87 & 159 & 5763 & 274 \\
\hline Lettonie & 831 & 0,6 & 75 & 164 & 5063 & 251 \\
\hline Grèce & 744 & 0,5 & 90 & 144 & 5164 & 406 \\
\hline Estonie & 675 & 0,5 & 92 & 97 & 6999 & 278 \\
\hline Slovénie & 605 & 0,4 & 86 & 110 & 5515 & 286 \\
\hline Luxembourg & 295 & 0,2 & 96 & 46 & 6420 & 307 \\
\hline Chypre & 151 & 0,1 & 100 & 23 & 6454 & 530 \\
\hline Malte & 40 & 0,0 & 100 & 6 & 5543 & $\mathrm{nc}$ \\
\hline UE-27 & 149100 & 100,0 & 91 & 23029 & 6475 & nc \\
\hline
\end{tabular}


Les incitations financières proposées par les entreprises pour essayer de lisser la courbe de collecte (prime à la saisonnalité) parviennent à améliorer la situation globale, mais d'autres facteurs techniques interfèrent parallèlement dans ce jeu.

Le lait collecté est utilisé pour fabriquer une palette de produits laitiers qui s'est profondément élargie, notamment en France où la diversité est exceptionnelle. Les efforts d'innovation déployés dans ce secteur (en termes de types de produits, de conditions de stockage, de marketing...) ont permis de séduire et de fidéliser de très nombreux consommateurs. D'après les statistiques publiées par le Centre National Inteprofessionnel de l'Economie Laitière (CNIEL), il est possible de rendre compte du poids de chaque type de produits laitiers dans l'utilisation du lait en France. Avec une production de 1,8 million de tonnes en 2011 , le secteur des fromages valorise plus du tiers de la matière sèche utile du lait collecté. Ce volume regroupe les fromages frais (667000 tonnes), les fromages à pâte molle (433 800 tonnes), les fromages à pâte pressée cuite (359 800 tonnes), les fromages à pâte pressée non cuite (238 600 tonnes), les fromages à pâte filée (62 300 tonnes), les fromages à pâte persillée (39 700 tonnes) et les fromages fondus (26 700 tonnes). Les 29 fromages français au lait de vache bénéficiant d'une Appellation d'Origine Contrôlée (AOC) représentent $13 \%$ des fromages (hors fromages frais) en volume et un peu moins de $25 \%$ en valeur (CNIEL 2012), soit un tonnage global de 158400 tonnes en 2010 (dont 47600 tonnes de Comté, 15100 tonnes de Reblochon, 14100 tonnes de Cantal et 13100 tonnes de Saint Nectaire). Les volumes résiduels de la collecte sont utilisés pour produire du beurre (410 000 tonnes), du lait en poudre (476000 tonnes), des laits conditionnés (3,5 milliards de litres), des yaourts et desserts (2,3 millions de tonnes), des crèmes conditionnées (415000 tonnes), de la poudre de lactosérum (617 900 tonnes) et des caséines (28 200 tonnes).

$\mathrm{Au}$ cours des dernières années, les industriels français ont privilégié les fabrications de Produits laitiers dits « de Grande Consommation » (les PGC représentent aujourd'hui $71 \%$ du lait collecté) et délaissé jusqu'à récemment les fabrications de produits dits « industriels » $(29 \%)$. Si cette stratégie s'est avérée gagnante pour de nombreux opérateurs, force est de constater que le marché français des PGC est devenu aujourd'hui mâture. A l'exception de quelques créneaux spécifiques, les volumes commercialisés ne progressent plus, d'autant que les innovations conduisent souvent à une diminution de l'utilisation d'ingrédients laitiers dans la fabrication des desserts. Cette stabilisation du marché des PGC, qui tend à exacerber les jeux concurrentiels entre marques, s'accompagne souvent d'une perte de création de valeur pour les acteurs de la filière (concurrence croissante via les prix de vente pour capter les consommateurs dans un contexte économique difficile). Ainsi, la demande mondiale croissante en produits laitiers industriels pourrait constituer à l'avenir une opportunité pour la filière française, d'autant plus que l'élasticité des prix est souvent plus forte à l'échelle internationale que sur le marché domestique (lieu où s'établissent de fortes tensions commerciales entre les industriels et le réseau de la grande distribution).

\section{3 / Les industriels de la trans- formation laitière}

En dépit d'un mouvement de concentration (Gardebroek et al 2010), le secteur industriel laitier français comporte encore de nombreuses entreprises laitières de taille moyenne ou petite (voire très petite dans le cas des fruitières qui contribuent utilement à la création de valeur ajoutée dans le secteur des fromages AOC). D'après la dernière enquête portant sur les Industries AgroAlimentaires (IAA), la France compte, en 2010, 335 entreprises laitières de plus de vingt salariés qui emploient au total 54500 salariés (13\% des emplois des IAA) et réalisent un chiffre d'affaires de 24,3 milliards d'euros $(17 \%$ du total des IAA). Le niveau de concentration des entreprises est, dans tous les cas, bien éloigné de celui de grands pays exportateurs tels que les Pays-Bas (Institut de l'Elevage 2010a, Tacken et al 2009), le Danemark ou la NouvelleZélande (Institut de l'Elevage 2010b). Dans les trois pays précités, les entreprises laitières (respectivement « FrieslandCampina », «Arla Foods » et «Fonter$r a »)$ sont pratiquement en situation de monopole, ce qui est très loin d'être le cas du leader français (Lactalis). Un classement effectué par la Rabobank montre que quatre entreprises françaises font parties des vingt leaders mondiaux du secteur (Rouault 2010) :

- Le groupe Lactalis. Avec un chiffre d'affaires de 15 milliards d'euros en 2011 , ce groupe collecte 14,5 milliards de litres de lait dans le monde et emploi 54000 salariés (dont 15000 en France) localisés dans 192 sites industriels. En 2011, il devient le numéro un mondial des produits laitiers, suite à l'acquisition de parts dans le groupe laitier italien Parmalat. La France compte pour seulement $27 \%$ dans le chiffre d'affaires global du groupe Lactalis, également très présent dans de nombreux autres Etats membres de l'UE (Italie, Espagne...) et plus globalement, sur la scène internationale. En France, ce groupe est le premier collecteur de lait de vaches avec environ 5 milliards de litres, soit près de $22 \%$ du total national. Leader sur le marché des fromages (y compris AOC) et numéro 2 en lait de consommation, le groupe Lactalis occupe aussi une position significative en produits frais (via Lactalis Nestlé Ultra Frais fondée en 2006 avec le groupe Nestlé) et en produits laitiers industriels.

- Le groupe Danone. Ce groupe occupe une place de leader en France pour les yaourts, les laits fermentés et les desserts lactés frais. Sa notoriété et son dynamisme à l'international (plus de la moitié des ventes se font dans les pays émergents) ne doivent cependant pas conduire à occulter que la contribution de ce groupe à la collecte nationale de lait demeure assez modeste (avec environ un milliard de litres, soit moins de 5\% du total national) et que cette collecte est assez fortement régionalisée (pas de présence, par exemple, dans l'Ouest de la France). La spécialisation «produit» de ce groupe est clairement affirmée et les investissements récents ne semblent pas démontrer une volonté des dirigeants de se diversifier (par exemple dans le secteur des fromages).

- Le groupe Sodiaal. Il se distingue des deux entreprises précédentes par son statut coopératif et sa structuration historique (fusion de 7 unions de coopératives régionales : Elnor, EstLait, Orlac, Riches Monts, Sully, Tempé-Lait et Ucalm). Ce groupe, doté d'une cinquantaine de sites industriels, collecte 4,1 milliards de litres de lait auprès de 12500 producteurs localisés dans soixante-six départements français. Leader national en lait de consommation et en raclette, il est " outsider " en produits laitiers frais mais dispose de positions significatives en produits laitiers industriels.

- Le groupe privé Bongrain, qui réalise près des deux tiers de son chiffre d'affaires en dehors de la France, est le leader français des spécialités fromagères et bénéficie également d'un bon positionnement en beurre, crème et produits industriels.

Ces quatre groupes représentent un peu plus de la moitié du lait de vache collecté en France. Le dynamisme de la filière laitière hexagonale tient donc aussi à la présence de nombreuses autres entreprises (MAAF 2012) dont notamment : le Groupe Bel qui dispose de 27 sites de production sur les 5 continents et distribue des fromages dans plus de 120 pays ; le Groupe Laïta, né en 2009 
de la fusion de trois coopératives de l'Ouest de la France (Coopagri Bretagne, Even, Terrena), collecte 1,3 milliard de litres de lait, réalise $65 \%$ de son chiffre d'affaires en France et occupe une place de leader sur plusieurs marchés de grande consommation : les beures moulés tradition, les yaourts « gourmands 》 et les poudres de lait ; en janvier 2013, les deux groupes coopératifs Agrial et Eurial ont annoncé la fusion de leurs activités laitières pour donner naissance au deuxième groupe laitier coopératif ( 2 milliards de litres collectés auprès de 5200 adhérents) ; le Groupe Senoble, dont le siège social est localisé dans le département de l'Yonne réalise près des deux tiers de son chiffre d'affaires à l'international; le Groupe $3 A$, qui collecte 430 millions de litres de lait de vache dans 23 départements du Sud-Ouest de la France; d'autres entreprises peuvent également être citées telles que le Groupement des Laiteries Coopératives de Charentes-Poitou (GLAC), le groupe Ermitage, la Prospérité fermière, Coralis, les Maîtres laitiers du cotentin, les Laiteries de Saint Denis de l'Hôtel, les Laiteries Triballat, la Coopérative d'Isigny Sainte-Mère, etc.

A côté de ces entreprises laitières bien connues, la France compte aussi de nombreuses structures de très petite taille. Ces unités, souvent orientées vers la production fromagère sous signe de qualité (Dervillé 2012), contribuent à la création d'emplois dans des zones rurales défavorisées et permettent aux producteurs de bénéficier d'une meilleure valorisation de leur lait (surtout en Franche-Comté et dans les Alpes). Plus globalement, les micro-entreprises laitières françaises (932 entités de moins de 20 salariés et moins de 5 millions d'euros de chiffre d'affaires) regroupent 4300 emplois pour 1,2 milliard d'euros de chiffre d'affaires. Parmi ces microentreprises, 313 collectent moins de 10 millions de litres par an.

Outre la question de la taille, l'hétérogénéité des acteurs de la transformation laitière se manifeste aussi au niveau de leur ancrage territorial, de leur spécialisation " produit », de leur positionnement éventuel sur les marchés internationaux, de leurs stratégies d'investissements (innovation) et de leur forme juridique (privées vs coopératives). Avec $54 \%$ de la collecte laitière nationale, le secteur coopératif joue un rôle important. Du fait de contraintes historiques et des choix stratégiques opérés par les dirigeants, les coopératives réalisent une part plus importante de la production nationale de lait de consommation $(66 \%)$, de poudres $(53 \%)$ et de beurre $(51 \%)$, que de fromages $(44 \%)$. De même, elles exportent moins, proportionnellement aux volumes collec- tés, sur les marchés internationaux que les entreprises privées.

Ces dernières années, de nombreux sites devenus obsolètes pour des raisons technologiques ou ayant une taille jugée insuffisante ont été fermés. En concentrant géographiquement leur activité et en augmentant la taille de leurs sites industriels, les transformateurs cherchent à satisfaire plusieurs ambitions : $i$ ) optimiser les coûts de production (coûts de collecte du lait dans les exploitations, coûts de transformation et coûts d'acheminement des produits laitiers vers les bassins de consommation) pour rester compétitif dans un marché domestique devenu mâture et concurrentiel ; ii) moderniser les outils industriels pour s'adapter aux exigences actuelles de productivité des facteurs; iii) atteindre une taille critique pour développer les exportations et renforcer les compétences acquises en termes de technologie, d'innovation, de marketing et de commerce. Cette concentration des opérateurs industriels est objectivement mesurable, par exemple, au travers de la part de la production nationale d'un type de produit qui relève des dix premiers sites industriels (FranceAgriMer 2010). En utilisant cette approche, il apparaît que les dix premiers sites contribuent pour $95 \%$ à la production de fromages fondus, $88 \%$ à celle d'Emmental, $79 \%$ à celle de beurre, $69 \%$ à celle de crème conditionnée, $67 \%$ à celle de poudre de lactosérum, $57 \%$ à celle des ultra-frais, $55 \%$ à celle des laits conditionnés, $53 \%$ à celle du lait en poudre, $52 \%$ à celle des fromages à pâtes pressées non cuites et $47 \%$ à celle des fromages à pâtes molles.

Le renforcement de la concurrence, l'exigence économique d'une présence renforcée sur les marchés tiers, l'amélioration des infrastructures de transport (qui favorise les flux commerciaux), les progrès technologiques (efficacité des procédés, automatisation...) et le rôle décroissant des pouvoirs publics dans la régulation de l'offre (fin programmée des quotas laitiers) sont autant de facteurs qui devraient concourir à la poursuite du processus engagé de restructuration des outils industriels au sein de la filière laitière française. La création de valeur ajoutée tout au long de la filière et la dynamique liée des emplois tient moins à la multiplicité des acteurs qu'à la capacité des entreprises existantes d'investir, d'innover et de capter une part de la croissance de la demande mondiale. Dans le secteur laitier, les restructurations industrielles feront toujours l'objet d'une attention particulière des pouvoirs publics en raison non seulement des emplois localisés, mais aussi des interactions évidentes entre cette activité et l'occupation du territoire.

\section{4 / Les échanges de produits laitiers}

Les échanges internationaux de produits laitiers représentent l'équivalent de 54 milliards de litres de lait en 2011 (sans prendre en compte le commerce intra-communautaire), soit $7 \%$ de la production laitière mondiale (Institut de l'Elevage 2012a). Compte tenu du caractère périssable des produits laitiers et d'une structuration du marché autour de bassins régionaux, ce taux est plus faible que celui observé dans d'autres filières comme les céréales, les viandes, le soja, etc. Au cours de la dernière décennie, les échanges internationaux de produits laitiers ont connu une croissance plus rapide que celle de la production, tout particulièrement dans le cas des poudres (maigres et grasses) et des fromages.

Les principaux importateurs de produits laitiers sont, par ordre décroissant, la Chine (de 2 milliards de litres en équivalent lait en 2006 à 5,5 milliards de litres en 2011), la Russie (environ 5 milliards de litres en 2011), l'Algérie (3 milliards de litres), le Mexique (2,2 milliards de litres), l'Egypte (2 milliards de litres), les Etats-Unis (1,9 milliard de litres), le Japon (1,8 milliard de litres) et l'UE-27 (1,5 milliard de litres). Si les importations européennes sont dérisoires au prorata de la production domestique (environ 1\%), les flux commerciaux entre Etats membres sont assez conséquents ; ils permettent non seulement de palier à la situation déficitaire de plusieurs Etats membres (dont le Royaume-Uni, l'Italie et l'Espagne), mais également de satisfaire l'exigence des consommateurs européens pour des produits laitiers diversifiés (surtout pour les fromages).

Les exportateurs de produits laitiers sont peu nombreux (International Dairy Fédération 2010). Avec des exportations qui s'élèvent à 16 milliards de litres en 2011 (en équivalent lait), soit plus de $90 \%$ de la production intérieure, la Nouvelle-Zélande occupe le premier rang mondial. Avec un coût de production du lait parmi les plus compétitifs et une proximité géographique avec les pays asiatiques importateurs, ce pays a doublé ses exportations en dix ans. $\mathrm{La}$ contribution de ce pays aux échanges internationaux de produits laitiers $(29 \%$ en volume) est très nettement supérieure à sa part dans l'offre mondiale de lait (moins de 3\%). A lui seul, ce pays exporte plus de produits laitiers que les 27 Etats membres de l'UE réunis. Les exportations européennes représentent environ 15 milliards de litres, soit $10 \%$ de la production communautaire. Les autres grandes zones exportatrices sont les Etats-Unis (en croissance depuis dix ans), l'Australie (en baisse du fait des 
difficultés rencontrées au niveau de l'offre), l'Argentine (en légère croissance au profit d'abord des pays voisins de l'Amérique du Sud) et, plus loin derrière, la Biélorussie, l'Uruguay et l'Ukraine. Si les européens occupent le premier rang sur le marché des fromages (plus du tiers des flux internationaux) et de la poudre de lait écrémé, ils sont positionnés loin derrière la NouvelleZélande pour les exportations de beurre et de poudre grasse.

Dans ce cadre international, la France occupe le deuxième rang européen en termes de balance commerciale en produits laitiers, derrière les Pays-Bas. Avec un solde de 3,4 milliards d'euros en 2011 (contre 2 milliards d'euros en 2000), le secteur laitier contribue donc à la situation positive de la balance commerciale agro-alimentaire française (+ 11,6 milliards d'euros en 2011). L'amélioration de ce solde tient surtout aux secteurs des fromages et aux pays tiers non européens.

La France occupe également le deuxième rang des pays exportateurs de produits laitiers de 1'UE-27, derrière l'Allemagne, mais devant les Pays-Bas, la Belgique, l'Italie, le Danemark et l'Irlande. Les exportations françaises de produits laitiers (hors produits à base de

Figure 1. Les échanges extérieurs de la France en produits laitiers (milliards d'euros). Source : Eurostat d'après Douanes.

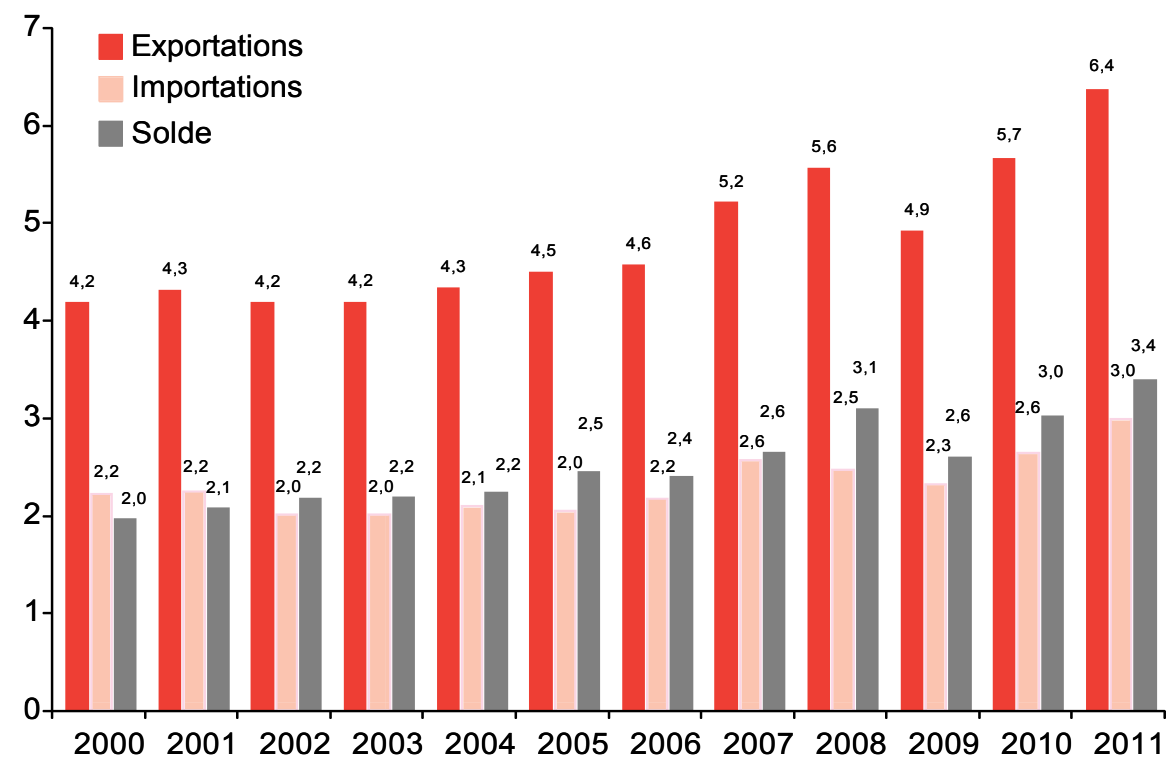

lait : glaces, aliment d'allaitement pour animaux et préparations alimentaires) ont augmenté de $35 \%$ au cours de la dernière décennie en passant de 4,2 à 6,4 milliards d'euros entre 2000 et 2011 (figure 1 et 2). Elles ont progressé pour toutes les catégories de produits laitiers à l'exception de la poudre de lait entier (- 257 millions d'euros). Les fromages, qui représentent $45 \%$ du total des exportations, ont joué un rôle moteur dans cette dynamique (les exportations sont passées de 1,9 à 2,8 milliards d'euros au cours de cette même période). D'autres secteurs ont également contribué à la hausse des exportations françaises: le lait infantile ( +332 millions d'euros), la poudre de lait écrémé $(+302$ millions

Figure 2. La balance commerciale de la France en produits laitiers en 2011 (millions d'euros). Source : Eurostat d'après Douanes.

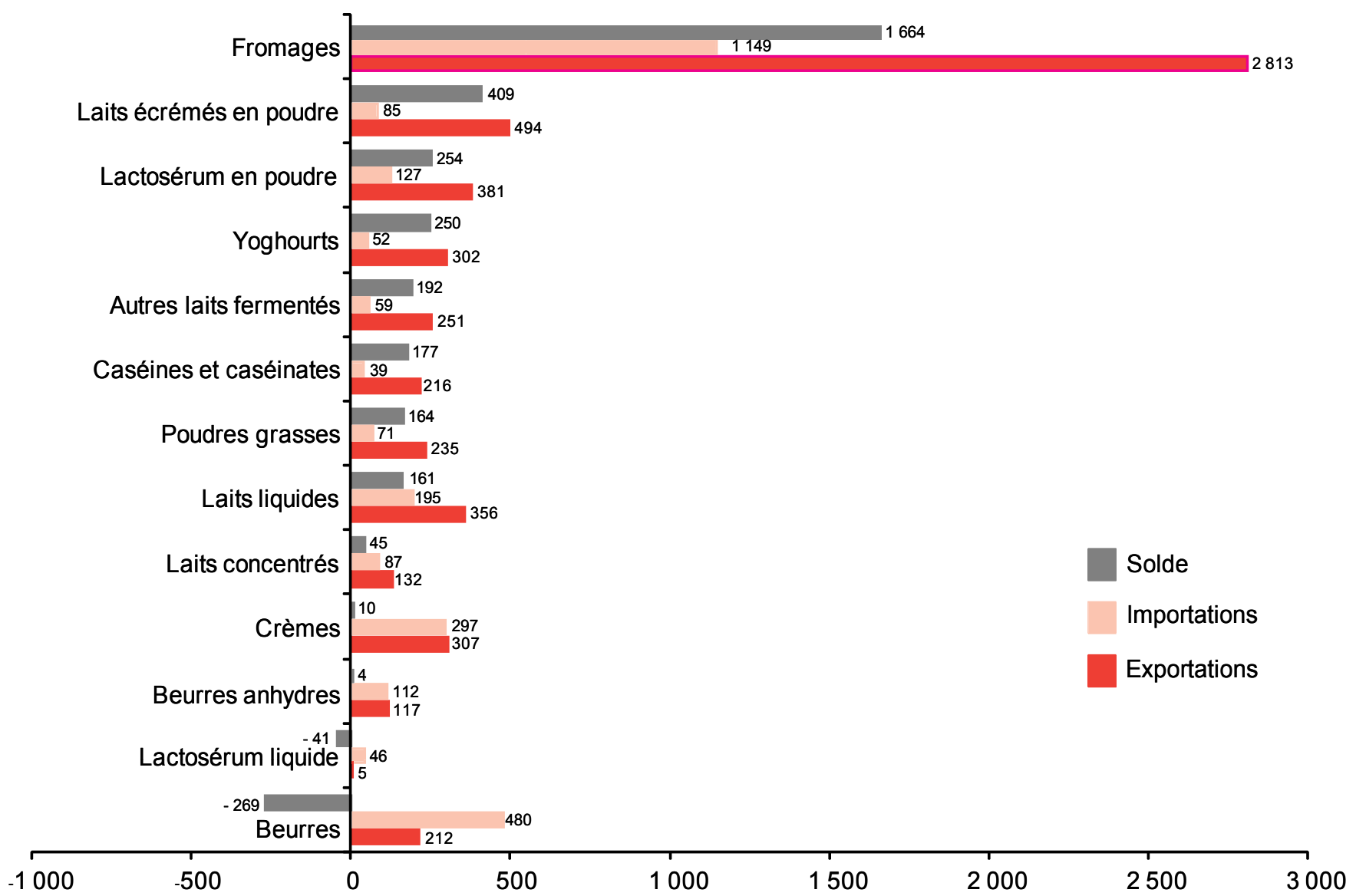


d'euros), les yaourts et autres produits laitiers fermentés $(+271$ millions d'euros), la poudre de lactosérum $(+167$ millions d'euros) et la crème ( +154 millions d'euros). En 2011, les exportations françaises de produits laitiers (en valeur) sont orientées pour $71 \%$ vers les Etats membres de l'UE et pour $29 \%$ vers les pays tiers, essentiellement au bénéfice des Etats-Unis, de la Suisse, du Japon, de la Russie et de l'Algérie. La part des pays tiers (non UE) dans le total des exportations est particulièrement importante pour le lait infantile (75\% du total), la poudre de lactosérum $(50 \%)$, la poudre de lait écrémé (49\%), les caséines $(47 \%)$ et la poudre de lait entier ( $45 \%)$; elle est plus modeste pour les fromages $(20 \%)$, les laits liquides $(10 \%)$, les laits concentrés $(3 \%)$ et les yaourts $(2 \%)$.

En dépit d'une production laitière abondante et d'une grande diversité de produits, la France importe une quantité non négligeable de produits laitiers, à $96 \%$ en provenance de pays membres de l'UE. Malgré la baisse des droits de douane et l'ouverture de contingents d'importations, suite aux précédents accords multilatéraux de l'Organisation Mondiale du Commerce (OMC), les achats en provenance de l'Océanie, des Etats-Unis ou de l'Amérique du Sud sont restés marginaux. La France se positionne au quatrième rang des pays importateurs de l'UE-27 derrière l'Allemagne, le Royaume-Uni et l'Italie. Les importations françaises de produits laitiers ont progressé de $42 \%$ entre 2000 et 2011 (en passant de 2,1 à 3 milliards d'euros). Cette hausse s'explique pour près de la moitié par la dynamique propre au secteur des fromages.

D'après les estimations de l'OCDE et de la FAO, le commerce mondial (hors intra-UE) des fromages devrait progresser d'environ $20 \%$ entre 2010 et 2021. La concurrence entre les pays européens pour capter une partie de ces volumes supplémentaires sera, dans un contexte de suppression des quotas laitiers, vive. Pour bénéficier de ces nouveaux marchés, et ainsi ouvrir de nouvelles perspectives de développement à la production laitière hexagonale, les industriels français devront renforcer leurs stratégies de positionnement sur les marchés tiers où ils sont, pour le moment encore, moins présents que leurs concurrents allemands ou néerlandais. Au niveau intra-communautaire, les acteurs industriels français pourraient bénéficier de la situation déficitaire en lait de près de la moitié des Etats membres. Les pays du sud de l'Europe ayant des conditions climatiques de production plus difficiles que les pays du nord et des coûts de production plus élevés, les producteurs français pourraient bénéficier, demain, de nouvelles opportunités de dévelop- pement. L'intensité de ce mouvement dépendra essentiellement des stratégies d'investissement déployées par les industriels et, aussi, de l'évolution des coûts de transport.

\section{5 / La volatilité des prix et des revenus}

En France, le prix du lait payé au producteur par les laiteries (prix toutes primes comprises, toutes qualités confondues, ramené à un lait standard : $38 \mathrm{~g} / \mathrm{L}$ de matière grasse et $32 \mathrm{~g} / \mathrm{L}$ de matière protéique) s'est élevé, en moyenne sur les treize années de la période 2000 à 2012, à $300 € / \mathrm{t}$ (en prix courant). Pour une campagne donnée, le niveau de prix varie d'une exploitation à l'autre principalement en fonction de la teneur du lait en matière grasse et en matière protéique, de la qualité bactériologique du lait, de son mode de valorisation (production de fromages $\mathrm{AOC}$ à haute valeur ajoutée, vente directe...), de la saisonnalité (des primes sont souvent octroyées pour encourager la production de lait en été), de l'adhésion ou non de l'éleveur à un dispositif de contrôle des performances et, de plus en plus, des réussites commerciales ou des difficultés de l'entreprise partenaire. Sur ce dernier point, et dans la perspective de la fin des quotas laitiers, il est utile de rappeler que les entreprises les plus performantes n'entendent pas nécessairement payer plus cher leur approvisionnement que les entreprises les moins compétitives. Dans un contexte concurrentiel, un alignement des prix s'opère toujours plus ou moins rapidement entre les fournisseurs.
Au cours de la dernière décennie, le prix moyen du lait payé au producteur a varié d'une année à l'autre sous l'influence essentielle des décisions inhérentes à la PAC et de la fluctuation des prix internationaux des produits laitiers. Historiquement reconnu pour être assez stable, le prix du lait a d'abord baissé entre 2003 et 2006 suite à la modification des règles de l'Organisation Commune de Marché (OCM) du lait et des produits laitiers. Cette réforme s'était, en effet, traduite par une baisse du prix institutionnel du beurre et de la poudre de lait écrémé compensée par l'octroi d'une aide directe attribuée à la tonne de quota (35,5 euros par tonne), puis intégrée (à partir de 2006) au montant des aides découplées (droits à paiement unique). Après une remontée des cours en 2007, et plus encore en 2008, les prix se sont effondrés en 2009 en raison principalement de la détérioration rapide des cours internationaux des produits laitiers industriels. Les trois dernières années ont été plus favorables (figure 3).

La période récente (2007-2012) a donc été caractérisée par une forte volatilité des prix, tant des produits commercialisés que des intrants (Boussard 2010, Jamet 2011). Si la volatilité des prix agricoles n'est pas un phénomène nouveau, il n'est pas facile de hiérarchiser et de pondérer l'influence respective des différents facteurs qui y concourent (Chatellier 2011, FAO 2011, Gouel 2012) : la sensibilité de l'offre aux aléas climatiques ; l'inélasticité de la demande par rapport au prix ; la rigidité de l'offre à court terme (rigidité des cycles

Figure 3. Le prix du lait payé au producteur en France (euros courants par tonne, moyenne nationale). Source : FranceAgriMer.

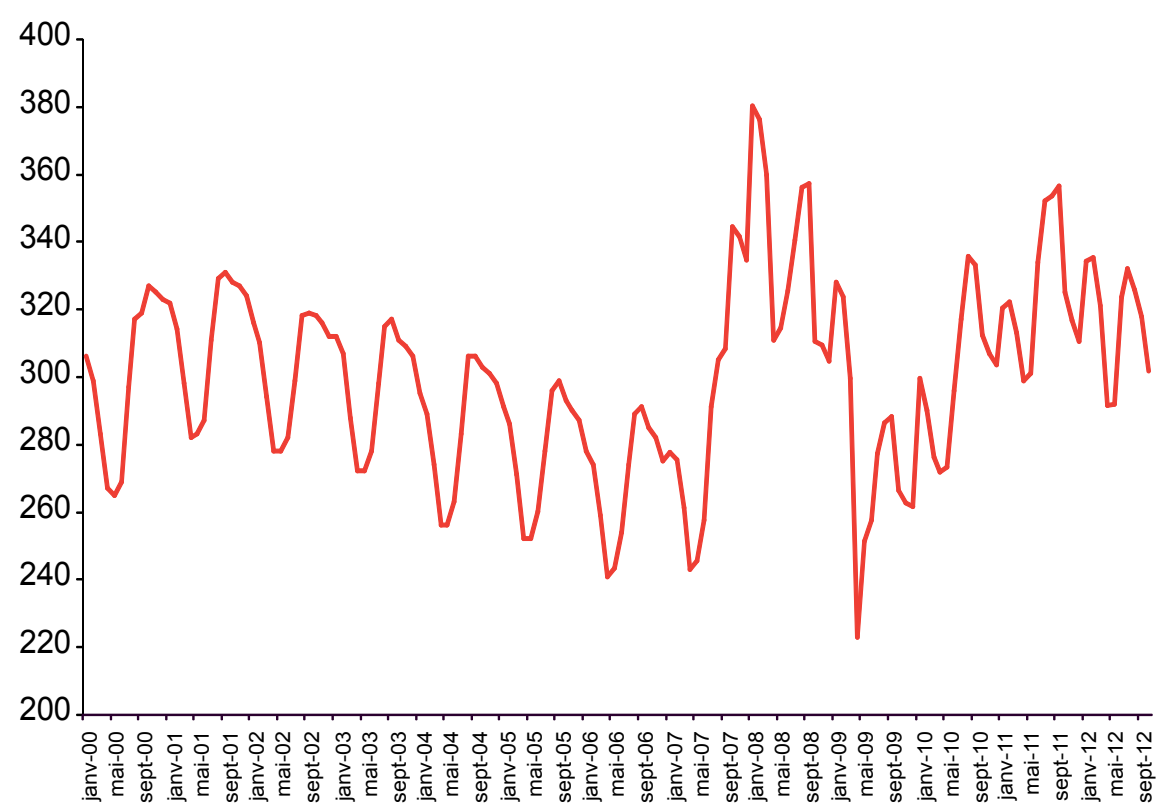


Figure 4. Le prix des intrants dans le secteur du lait de vache en France (IPAMPA, indice $100=2005$ ).

Source : Institut de l'Élevage d'après INSEE et Agreste.

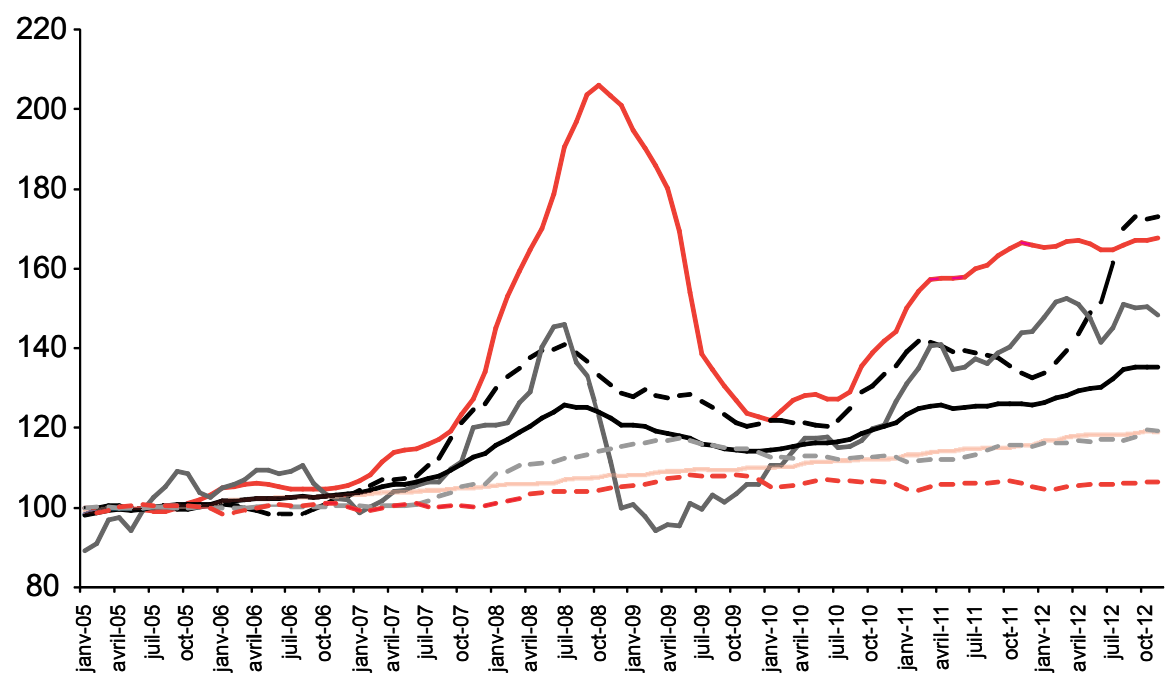

\section{— Engrais et amendements - Indice général \\ - - Produits de protection des cultures \\ - - Aliments achetés}

de production); la tonicité de la demande mondiale ; la variation du prix de l'énergie ; la variabilité des taux de change ; le manque de coordination internationale des politiques agricoles; la spéculation financière, etc.

La volatilité accentuée des prix internationaux des produits laitiers ne doit cependant pas masquer deux tendances importantes de l'économie laitière : l'évolution à la hausse du prix international des différents produits laitiers au cours de la précédente décennie ; le resserrement des écarts entre les prix des principaux exportateurs concurrents (Océanie, USA, Amérique du Sud) et ceux pratiqués par l'UE.

Dans le secteur laitier, une baisse des prix internationaux influence assez directement la valeur ajoutée dégagée par les acteurs de la transformation, qui cherchent alors à reporter, du moins pour partie, le manque à gagner vers les producteurs via une baisse du prix d'achat de la matière première (le lait). Cette stratégie des transformateurs laitiers intervient dans un contexte où, d'une part, les pouvoirs publics ont démantelé (ou fortement limité) la plupart des outils de régulation des marchés agricoles (conditions plus restrictives à l'ouverture du stockage public, baisse des fonds alloués aux restitutions aux exportations, réduction des aides versées en faveur d'un développement de la consommation) et, d'autre part, les centrales d'achats, fortement concentrées, n'acceptent que difficilement une hausse du prix d'achat de leurs approvisionnements. En Allemagne, les centrales d'achat semblent plus réactives dans les varia-

\section{- Produits et services vétérinaires - Energie et lubrifiants$$
\text { - - Semences et plants }
$$

tions à la baisse, mais aussi à la hausse, des prix.

La volatilité des prix des produits laitiers à la consommation a été nettement plus faible que celle observée au niveau de la production pour deux raisons essentielles : i) la part du produit agricole brut dans le bien final est souvent faible en valeur, surtout pour les produits transformés à haut degré de sophistication ; ii) du fait de la structure concentrée du réseau de distribution des produits alimentaires, de la diversité des produits proposés et de la pression qui s'exerce aujourd'hui sur le budget des en France (milliers d'euros courants). Source : SSP - Agreste - RICA. ménages, les jeux concurrentiels sont particulièrement animés (promotions sur les produits, substitutions entre produits/marques...) et concourent à limiter les variations de prix au niveau des consommateurs.

Pour les producteurs de lait, la volatilité du prix du lait doit être mise en relation avec la forte augmentation récente de leurs coûts de production. D'après les calculs réalisés par l'Institut de l'Elevage sur la base de l'Indice des Prix d'Achat des Moyens de Production Agricole (IPAMPA), le prix des intrants et des autres moyens de production (matériels, équipements, bâtiments) utilisés dans le secteur du lait de vache a augmenté de $35 \%$ en moyenne entre 2005 et fin 2012 en France. Cette forte augmentation s'explique essentiellement par la hausse substantielle du coût des engrais, de l'énergie et des aliments pour animaux (figure 4). Compte tenu de la forte hétérogénéité des systèmes productifs, de la diversité des performances techniques et des choix stratégiques adoptés en termes d'investissements, la hausse du prix des intrants n'a pas contribué partout avec la même intensité à la hausse des coûts de production.

En moyenne, sur les sept années de la période 2006 à 2012 (en euros courants), le revenu moyen dans les exploitations laitières spécialisées françaises s'est élevé à 22900 euros par Unité de Travail Agricole (UTA) familiale (CCAN 2012). A titre de comparaison, la moyenne nationale (toutes exploitations confondues) s'est établie à 28300 euros, soit $23 \%$ de plus que les producteurs de lait ; parallèlement, les exploitations spécialisées en céréales et oléo-protéagineux

Figure 5. Le résultat courant avant impôts moyen par actif agricole non salarié

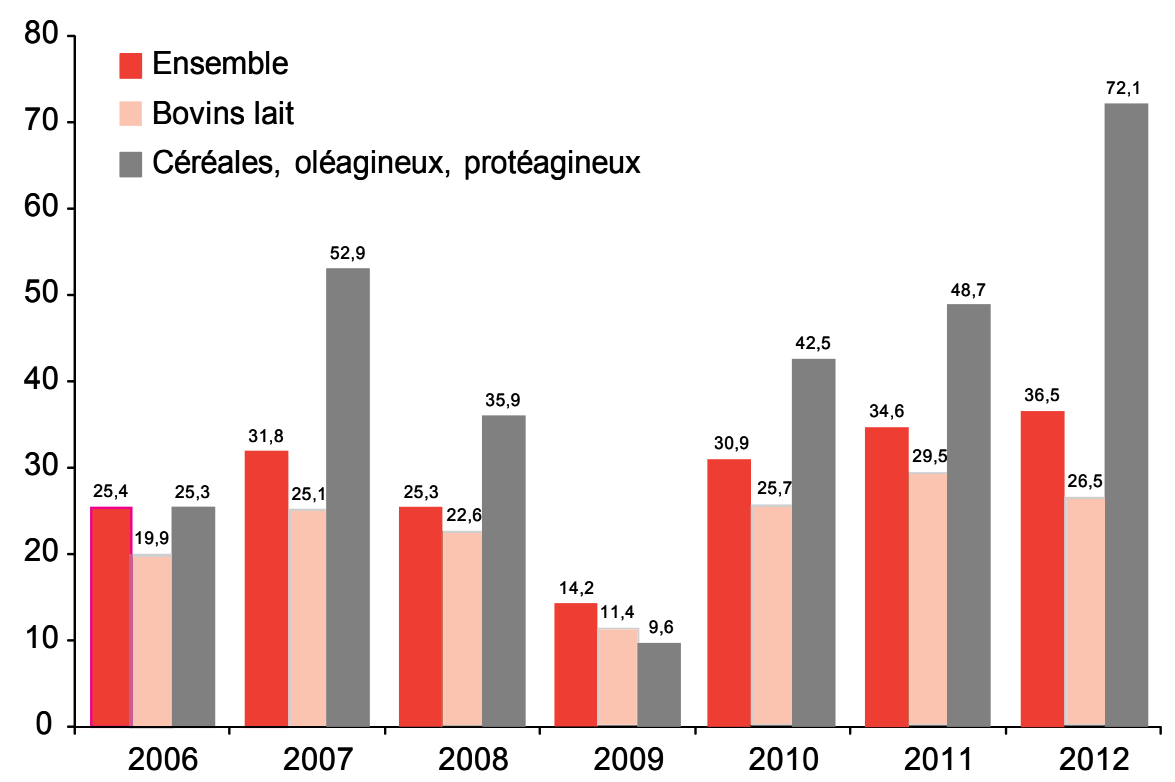


ont bénéficié d'un revenu moyen de 41000 euros, soit $78 \%$ de plus (figure $5)$. Après une période de stabilité du revenu, la volatilité des prix a provoqué des variations interannuelles intenses à partir de 2007. L'année 2009, qui a été la plus mauvaise pour les producteurs laitiers français, a entraîné des abandons de production laitière, et d'autant plus que certains producteurs s'inscrivaient déjà dans cette logique suite à la hausse du prix des céréales de 2007-2008; elle a aussi provoqué d'importants mouvements de protestation (Roullaud 2010), notamment au travers de l'Association des Producteurs de Lait Indépendants (APLI). Le différentiel de revenu entre les producteurs de lait et ceux spécialisés en céréales s'est très fortement accru au cours des trois dernières années, l'année 2012 constituant sur ce plan un record (respectivement 26500 euros par UTA familiale en lait contre 72100 euros en céréales), ce qui ne va pas sans poser des questions, dans le cadre des négociations sur la future PAC, quant aux modalités de distribution des soutiens publics à l'agriculture (Chatellier et Guyomard 2012).

Tableau 4. L'évolution du secteur laitier dans les régions françaises (1983/2010). Classement des régions par ordre décroissant des livraisons de lait.

Source : FranceAgriMer - SSP.

\begin{tabular}{|c|c|c|c|c|c|c|c|c|c|c|}
\hline & $\begin{array}{l}\text { Livraison } \\
\text { de lait (\%) }\end{array}$ & Producte & s de lait & effectifs) & $\begin{array}{r}\mathrm{Li} \\
\text { produc }\end{array}$ & $\begin{array}{l}\text { ison de I } \\
\text { ur (kg de }\end{array}$ & $\begin{array}{l}\text { par } \\
\text { par an) }\end{array}$ & $\begin{array}{r}\text { Effect } \\
(r\end{array}$ & $\begin{array}{l}\text { e vach } \\
\text { iers de }\end{array}$ & $\begin{array}{l}\text { laitières } \\
\text { tes) }\end{array}$ \\
\hline & 2010 & 1983 & 2010 & Var. (\%) & 1983 & 2010 & $\operatorname{Var}^{(*)}$ & 1983 & 2010 & Var. (\%) \\
\hline Bretagne & 21,5 & 66129 & 14182 & -79 & 84200 & 346100 & 4,1 & 1342 & 731 & -46 \\
\hline Pays de la Loire & 14,9 & 49843 & 10032 & -80 & 74500 & 340700 & 4,6 & 932 & 510 & -45 \\
\hline Basse-Normandie & 11,5 & 39760 & 7992 & -80 & 70500 & 329700 & 4,7 & 820 & 449 & -45 \\
\hline Rhône-Alpes & 6,1 & 36239 & 6601 & -82 & 39400 & 211700 & 5,4 & 482 & 275 & -43 \\
\hline $\begin{array}{l}\text { Nord-Pas-de- } \\
\text { Calais }\end{array}$ & 5,5 & 13851 & 4239 & -69 & 88500 & 297100 & 3,4 & 371 & 181 & -51 \\
\hline Lorraine & 5,3 & 14433 & 3574 & -75 & 91000 & 340900 & 3,7 & 340 & 189 & -44 \\
\hline Franche-Comté & 4,9 & 13130 & 4377 & -67 & 83700 & 256700 & 3,1 & 297 & 199 & -33 \\
\hline Auvergne & 4,7 & 25207 & 5939 & -76 & 40900 & 181300 & 4,4 & 414 & 232 & -44 \\
\hline Picardie & 3,9 & 10506 & 2471 & -76 & 99800 & 359000 & 3,6 & 261 & 128 & -51 \\
\hline Midi-Pyrénées & 3,6 & 17879 & 3339 & -81 & 56700 & 245400 & 4,3 & 330 & 154 & -53 \\
\hline Haute-Normandie & 3,6 & 11470 & 2480 & -78 & 81800 & 329800 & 4,0 & 270 & 134 & -50 \\
\hline Poitou-Charentes & 2,9 & 21004 & 1686 & -92 & 42700 & 389600 & 9,1 & 279 & 99 & -65 \\
\hline $\begin{array}{l}\text { Champagne- } \\
\text { Ardenne }\end{array}$ & 2,8 & 8633 & 1938 & -78 & 88500 & 329300 & 3,7 & 201 & 102 & -49 \\
\hline Aquitaine & 2,7 & 19318 & 2365 & -88 & 41700 & 260000 & 6,2 & 267 & 110 & -59 \\
\hline Centre & 1,9 & 10875 & 1146 & -89 & 51100 & 384000 & 7,5 & 167 & 65 & -61 \\
\hline Bourgogne & 1,6 & 9482 & 1061 & -89 & 47200 & 337000 & 7,1 & 166 & 61 & -64 \\
\hline Alsace & 1,2 & 7303 & 816 & -89 & 42300 & 343900 & 8,1 & 91 & 45 & -51 \\
\hline Limousin & 0,7 & 5423 & 661 & -88 & 36300 & 256900 & 7,1 & 59 & 32 & -46 \\
\hline L. Roussillon & 0,4 & 2510 & 573 & -77 & 31300 & 145800 & 4,7 & 43 & 21 & -53 \\
\hline Ile de France & 0,2 & 673 & 102 & -85 & 69400 & 410100 & 5,9 & 13 & 7 & -48 \\
\hline PACA & 0,1 & 1277 & 192 & -85 & 30400 & 134400 & 4,4 & 21 & 7 & -66 \\
\hline France & 100,0 & 384945 & 75766 & -80 & 65800 & 301900 & 4,6 & 7166 & 3729 & -48 \\
\hline
\end{tabular}

(*) Coefficient multiplicateur entre 1983 et 2010.
Au demeurant, et du fait de la forte hétérogénéité du secteur, le revenu moyen des producteurs de lait français masque, comme dans toutes les orientations de production, une forte dispersion. Le niveau de revenu par emploi ne tient pas uniquement à la taille de l'entreprise (Béguin et Roussel 2006), mais plus souvent à la combinaison de plusieurs critères clés : la productivité du travail (mesurée au travers du quota laitier ou du chiffre d'affaires par emploi); l'efficacité économique du système productif (ratio « Excédent Brut d'Exploitation/ produit brut ») ; les conditions économiques à l'installation et les stratégies d'investissements (ratio " chiffre d'affaires/capital total »).

\section{2 / La forte diversité des exploitations laitières fran- çaises}

Depuis l'instauration des quotas laitiers en 1984, la politique laitière française a tenté de poursuivre deux objectifs majeurs, à savoir maintenir une répartition géographique équilibrée de la production laitière et favoriser le développement d'exploitations laitières de taille moyenne en privilégiant l'installation de jeunes agriculteurs. Pour y parvenir, et dans le cadre des latitudes offertes par la règlementation communautaire, plusieurs règles ont été instituées. Pour éviter une hausse des coûts de production et contenir les investissements lors de l'installation, les quotas laitiers ne peuvent être vendus entre producteurs de lait comme cela est le cas dans d'autres pays européens. De plus, les transferts de quotas laitiers ne se font qu'à l'occasion de transferts fonciers (par vente ou location) et sont étroitement contrôlés et réglementés par les pouvoirs publics (Boinon 2012) : ils sont gérés par la commission mixte départementale qui a le pouvoir de prélever une partie des quotas transférés pour les redistribuer gratuitement à des catégories d'agriculteurs considérées comme prioritaires (jeunes agriculteurs, petits agriculteurs...). Pour favoriser la restructuration du secteur et améliorer sa compétitivité, plusieurs programmes de cessation de l'activité laitière ont été mis en œuvre ; ceux-ci prévoyaient l'octroi de primes spécifiques aux agricul- 
teurs qui renonçaient, de manière définitive, à produire du lait sur les terres auxquelles le quota était rattaché.

La réussite a été manifeste dans la poursuite du premier objectif. Ainsi, en 2010, la production laitière est encore présente dans $92 \%$ des Petites Régions Agricoles (PRA) françaises et dans 84\% des cantons (hors Paris, petite couronne, et zone méditerranéenne). De même, d'après l'enquête laitière annuelle de 2011, tous les départements français ont une activité laitière (certes parfois mineure), avec une collecte encore partiellement assurée dans tous les départements sauf la Corse et le Var. En raison des réglementations nationales, la localisation de la production laitière, ou du moins des droits à produire, a très peu évolué au cours de deux dernières décennies comparativement à ce qui a été constaté dans d'autres pays tels que l'Italie, le Royaume-Uni, plus récemment l'Allemagne (Institut de l'Elevage 2012c). Quelques migrations de quotas ont été observées au sein de certains départements (Picardie, Nord Pas-deCalais, Franche-Comté) ou à l'échelle de certaines régions hétérogènes (MidiPyrénées, Aquitaine), au profit des zones à vocation laitière plus affirmée. L'étude des mouvements de quotas se révèle cependant insuffisante pour mesurer les variations de production/livraison en raison des forts taux de sous-réalisation constatés dans certains départements.

En dépit de la forte restructuration du secteur, la production laitière française résulte toujours d'une très grande diversité de modèles productifs et de territoires (Pflimlin et al 2009). Cette diversité se retrouve au niveau des conditions de production (climat, relief, potentiel agronomique), des modèles productifs adoptés (spécialisation, intensification, alimentation des animaux...), des formes d'organisation du travail (exploitations individuelles vs sociétés), des technologies utilisées (développement de la robotisation), des performances techniques obtenues ou encore des résultats économiques dégagés. Si la fin des quotas laitiers est susceptible d'entraîner une certaine recomposition du territoire laitier français (par une concentration accentuée de l'offre dans les bassins dotés d'avantages comparatifs), il est fort probable que cette diversité des modèles productifs persistera encore. Elle présente l'avantage économique non négligeable d'offrir aux opérateurs d'aval une grande variété de produits et ainsi de contribuer à stimuler les niveaux internes de consommation (comme dans le cas des fromages).

En France, le nombre d'exploitations laitières a baissé de $80 \%$ depuis la mise en œuvre des quotas laitiers, en passant de 384900 exploitations en 1983 à 75700 en 2010 (tableau 4). Bien que particulièrement soutenu, ce rythme de restructuration est parmi les plus faibles des Etats membres de l'UE. Le taux annuel de restructuration a, par exemple, atteint près de $10 \%$ au cours des dix dernières années en Espagne (Institut de l'Elevage 2009c) et au Danemark. La vitesse de restructuration a été plus élevée dans les régions dites "intermédiaires ॥ où domine la polycultureElevage (Poitou-Charentes, Aquitaine, Centre) que dans les régions spécialisées de montagne (Franche-Comté et Auvergne) où les potentielles substitutions agricoles sont plus limitées. Les livraisons de lait sont passées, dans le même temps, de 65800 litres par exploitation en 1983 à 3306001 en 2011, avec une accélération très nette au cours des cinq dernières années, surtout en zone de plaine (jusqu'à $+47 \%$ par point de collecte en Basse-Normandie et $+49 \%$ en Haute-Normandie entre 2006 et 2011). L'écart entre les dimensions moyennes des exploitations de plaine et de montagne s'accroît considérablement (autant entre 2007 et 2010 qu'entre 2000 et 2007) et cette divergence dans les structures d'exploitation a toutes les chances de se poursuivre à l'avenir. En plaine, la disponibilité accrue de volumes de production dans le cadre de la sortie progressive des quotas laitiers, ainsi que des évolutions réglementaires, ont favorisé l'émergence rapide de grandes exploitations laitières " à la française ». D'après les données du recensement agricole de 2010, les 2000 plus grands ateliers géraient un million de litres de moyenne. Et la moitié de ces grandes exploitations laitières étaient situées dans les zones de polyculture-élevage (qui ne représentent que le tiers de l'activité laitière nationale). Du fait de l'amélioration de la productivité des animaux, le cheptel de vaches a pratiquement été divisé par deux depuis l'instauration des quotas laitiers, avec des écarts régionaux influencés, pour partie, par le poids relatif des différentes races, une intensification accrue dans les zones de polyculture-élevage et des dynamiques laitières parfois très négatives $(30 \%$ de baisse de cheptel dans de larges zones du Sud-Ouest rien qu'entre 2000 et 2010).

\section{1 / Une très forte hétérogénéité territoriale}

Dans un contexte où les jeux concurrentiels se renforcent, la question de la répartition territoriale de la production laitière prend de plus en plus d'importance dans les débats. Ainsi, les caractéristiques naturelles, organisationnelles et socio-économiques des différents territoires sont de plus en plus discutées en termes d'atouts concurrentiels ou de contraintes (Ben Arfa 2011). A partir d'une valorisation des données du Recensement agricole de 2010, un portrait synthétique du secteur laitier français est proposé ci-après, sur la base d'une grille méthodologique (zonage) élaborée dans de précédents travaux conduits par l'Institut de l'Elevage (Institut de l'Elevage 2009b). L'analyse de la situation du secteur laitier français est réalisée en considérant successivement quatre grandes zones laitières, à savoir les zones d'élevage de plaine ; les zones de polyculture-élevage; les zones de montagne ou de piémont; les zones non laitières (ou plus marginales). Les trois premières zones précitées font l'objet de subdivisions en fonction principalement des potentialités agricoles, de l'orientation des systèmes de production (dominance de systèmes spécialisés ou diversifiés), de la densité laitière (critère qui influe sur la probabilité de reconversion) et du massif considéré (carte 1).

a) La production laitière dans les zones d'élevage de plaine

Les zones dites « de plaine » rassemblent les principaux bassins laitiers français (hors montagne), à savoir : « l'Ouest » (zones d'élevage des régions Bretagne et Pays de la Loire et du département des Deux-Sèvres); la BasseNormandie et les zones mixtes herbemaïs ; les zones herbagères du NordOuest et du Nord-Est. Caractérisées par une forte densité d'exploitations laitières et de production laitière au $\mathrm{km}^{2}$, ces zones regroupent $45 \%$ des exploitations laitières françaises (soit environ 34000 en 2010) et assurent la moitié de la production laitière nationale (Chatellier et al 2008). Trois sous-zones sont distinguées selon un gradient d'intensification et la place relative de l'herbe et du maïs ensilage dans le système fourrager.

- Dans la zone « Ouest », la production laitière est le fait d'exploitations de taille moyenne ( 83 hectares), semiintensives $(1,63 \mathrm{UGB} / \mathrm{ha}, 6800$ litres de lait par vache et par an, 6000 litres de lait par ha de Surface Fourragère Principale - SFP) et utilisant largement le maïs ensilage (présent dans $96 \%$ des exploitations). En Bretagne, les exploitations laitières ont moins souvent un autre atelier de bovins à viande $(27 \%)$ que dans les Pays de la Loire (54\%); elles ont assez fréquemment un atelier hors-sol, avec une production significative dans $25 \%$ des cas. Le niveau d'intensification du cheptel laitier et l'existence d'atelier hors-sol a bien évidemment des conséquences sur les charges organiques calculées par hectare. Une part importante de la Bretagne, de l'Ouest de la Mayenne et du sud de la Manche ont une quantité d'azote organique voisine, 
Carte 1. La diversité du secteur productif laitier en France (2010).

Source: Agreste - Recensement agricole 2010 / Traitement Institut de l'Elevage.
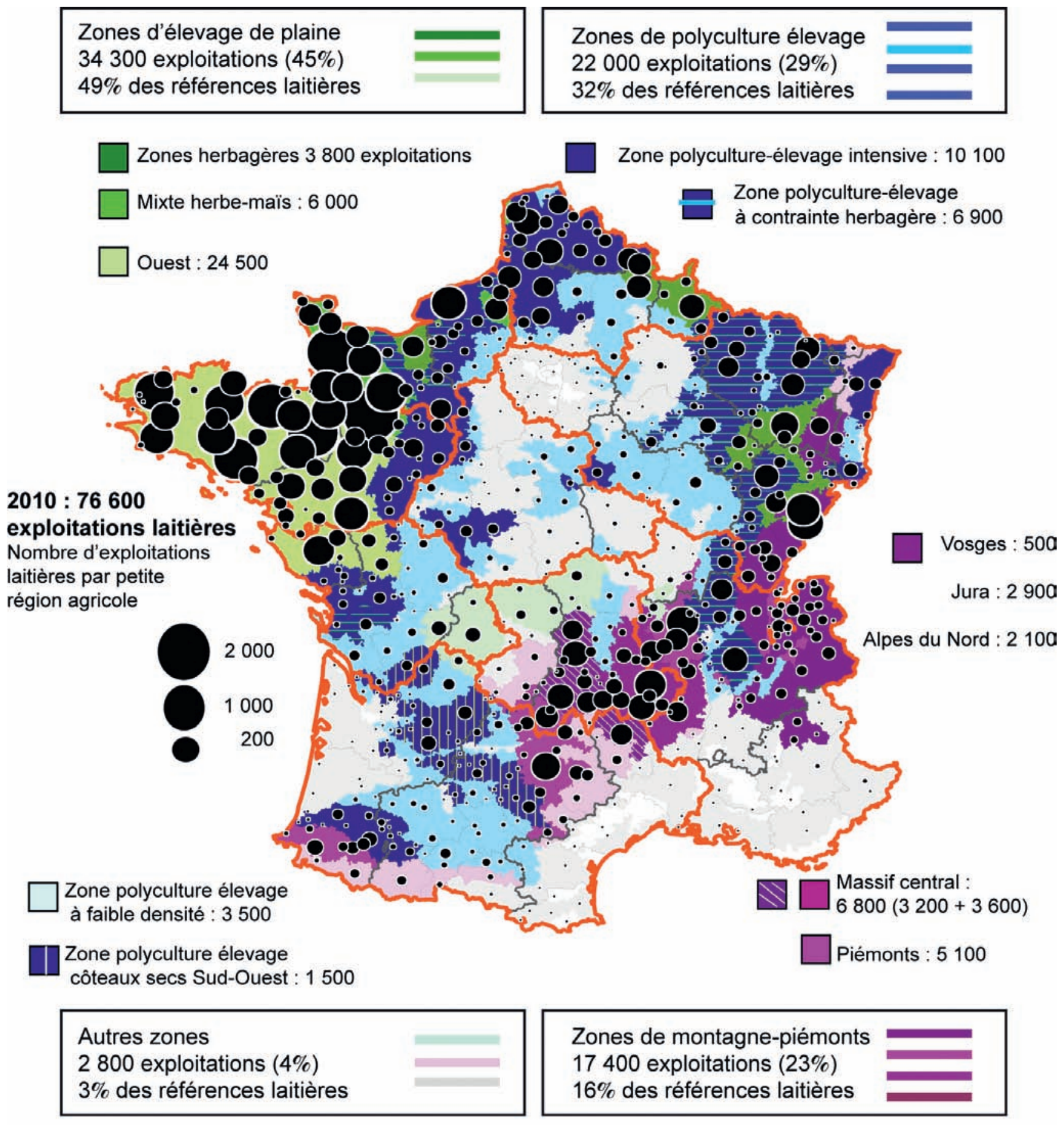

voire supérieure au seuil des $170 \mathrm{~kg}$ par hectare de surface d'épandage (Peyraud et al 2012, Gaigné 2012). La quantité de lait produite dans ces cantons est importante et beaucoup d'entre eux sont classés en zones d'excédents structurels ou en bassins de contentieux par rapport à la règlementation (Mougin et al 2008).

- Dans l'Ouest de la Basse-Normandie et les autres zones mixtes herbemaïs, l'élevage bovin, en particulier laitier, règne sans partage sur les productions agricoles, la mixité lait-viande y étant fréquente. Bien que les exploita- tions soient moins intensives que dans « l'Ouest » (5 900 litres par vache et par an) et utilisent plus d'herbe (les prairies naturelles et permanentes représentent, en moyenne, $42 \%$ de la SAU) dans leurs systèmes fourragers (Peyraud et al 2010), la densité laitière de la zone atteint des niveaux très élevés (180 000 litres de lait par $\mathrm{km}^{2}$ ). C'est donc la spécialisation qui porte cette densité moyenne à un niveau supérieur à celle de l'Ouest où l'activité agricole est plus diversifiée (carte 2).

- Dans les zones herbagères de plaine, la contrainte herbagère est portée à son maximum dans les cantons aux sols très argileux, parfois marqués par un certain relief et où les possibilités de labour sont très limitées. Dans ces zones, terres d'élevage historiques (Pays d'Auge, Thiérache, Bassigny-Chatenois...), un tiers des exploitations laitières n'utilisent pas ou très peu de maïs ensilage et les trois quarts associent un atelier de bovins à viande à l'activité laitière, le plus souvent avec des animaux consommateurs d'herbe (bœufs ou vaches allaitantes) pour utiliser une Surface Toujours en Herbe (STH) abondante (78 ha en moyenne). 
Carte 2. La densité de l'activité laitière sur le territoire français (2010).

Source : Agreste - Recensement agricole 2010 / Traitement Institut de l'Elevage.

\section{Densité de quota laitier (litres/km²) par Petite Région Agricole}

Source : Agreste Recensement agricole 2010 et FranceAgriMer - cartographie Institut de l'Elevage

\section{Densité d'exploitations laitières (nb/10 km²) par commune}

Densité d'exploitations laitières au 01/11/2009

Source : BDNI traitement Institut de l'Elevage

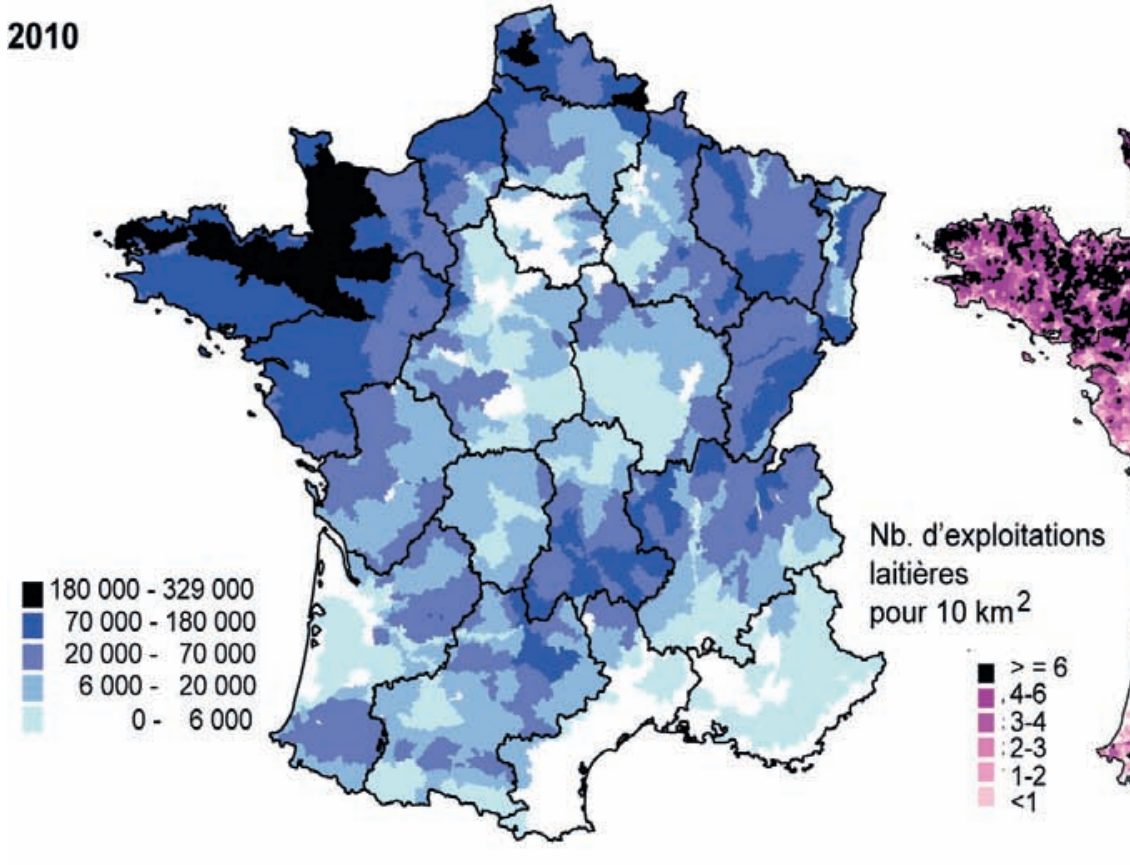

b) La production laitière dans les zones de polyculture-élevage

Les zones de « polyculture-élevage », qui rassemblent $29 \%$ des exploitations laitières françaises et $32 \%$ du quota laitier, regroupent l'essentiel des régions agricoles situées, géologiquement, dans les grands bassins sédimentaires (Bassin parisien, Bassin aquitain) et les plaines d'effondrement (Sillon Saône-Rhône, plaine d'Alsace). Les potentiels pédoclimatiques de ces différentes zones et la proportion de terres labourables expliquent l'orientation des systèmes de production : $55 \%$ pratiquent un système de polyculture-élevage ou associent des cultures spéciales (dans le Sud-Ouest) à l'activité laitière.

- Les zones de polyculture-élevage intensive correspondent aux bordures nord et ouest du Bassin parisien, à la plaine d'Alsace et au Sud Aquitain. Elles sont situées dans les bassins français aux meilleurs potentiels agronomiques et aux plus faibles contraintes d'utilisation des surfaces (peu de prairies permanentes). Les exploitations laitières, souvent fortement spécialisées, sont plus intensives qu'ailleurs $(1,90 \mathrm{UGB} / \mathrm{ha}$, 7100 litres de lait par vache et par an, 7200 litres de lait par ha de SFP) et utilisent largement le maïs ensilage. La forte pression foncière et des tailles d'exploitation « moyennes » (105 ha de $\mathrm{SAU}$ ) expliquent le maintien de la pro- duction laitière dans nombre de ces exploitations, malgré le bon potentiel agronomique et la possibilité de pratiquer des cultures à forte valeur ajoutée (betteraves, lin, légumes, pomme de terre).

- Les zones de polyculture-élevage à contrainte herbagère sont localisées plus particulièrement dans le quart nord-est de la France. Elles correspondent à des plateaux entrecoupés de larges vallées inondables (vallées de la Meuse, de la Moselle, du Doubs, de la Saône...). Dans ces régions, les terres agricoles sont pour partie labourables mais aussi assez largement occupées par d'incontournables STH (vallées argileuses et terrains accidentés). Si le drainage a souvent permis d'étendre les surfaces allouées aux cultures, ce mouvement est resté limité par la difficulté de travailler les sols argilo-calcaires et par l'insuffisance des réserves en eau sur certains plateaux. Ces exploitations, de grande dimension (148 ha de SAU), associent fréquemment lait, cultures de vente et production de viande (ce dernier atelier étant justifié par l'abondance de la STH). La place du maïs ensilage est plus faible que dans les zones de plaine ( $21 \%$ de la SFP en moyenne), mais elle est comparable ramenée au cheptel laitier (17 hectares pour 54 vaches laitières). Les zones rurales de ces régions sont souvent faiblement peuplées; l'agriculture et l'agro-alimentaire y occupent une place essen-tielle dans l'activité socio-économique.

Ces deux premières zones de polyculture-élevage correspondent à des bassins laitiers importants, présentant une densité de production moyenne, mais néanmoins solidement ancrés à côté des productions de grandes cultures, notamment grâce à une bonne implantation des industriels de la transformation. Ce n'est pas le cas des deux zones suivantes où la densité de production est nettement plus faible et se maintient difficilement.

- Les zones sèches du Sud-Ouest sont caractérisées par des sols souvent perméables (coteaux, causses) et au déficit hydrique estival très marqué. La production laitière, ancienne, y est encore souvent $(34 \%)$ pratiquée en association avec des activités agricoles très diverses (céréales, viticulture, arboriculture, melons, tabac, légumes, semences, palmipèdes...). Cependant, la tendance est nettement à la déprise laitière et à une concentration territoriale par défaut (repli sur des bassins de production en îlots) puisque, dans un contexte de forte restructuration, les exploitations les plus diversifiées se détournent davantage de la production laitière. Rares sont les systèmes fourragers qui n'intègrent pas de l'ensilage de maïs, mais cette culture, souvent irriguée, est réservée aux meilleures terres, ce 
qui en limite l'extension, et donc la contribution à l'alimentation des vaches laitières. Ce contexte finalement peu favorable à l'élevage d'herbivores explique la rareté des ateliers viande complémentaires dans cette zone (18\%, de loin le plus faible taux des zones de plaine), mais aussi sans doute la faible dynamique laitière.

- Dans les zones de polycultureélevage à faible densité laitière (Bourgogne, Centre, Poitou-Charentes, SudOuest), la dynamique du secteur est, là aussi, problématique. La forte restructuration laitière déjà opérée dans cette zone a cependant permis aux exploitations laitières résiduelles et désireuses de poursuivre cette activité de développer cet atelier et de disposer des références laitières parmi les plus élevées et en hausse très rapide (en moyenne 383000 litres par exploitation). Dans ces zones, la pérennité à long terme des exploitations n'est cependant pas acquise et sera influencée par l'évolution des rapports de prix entre les productions animales et végétales, les choix d'investissement des industriels de la transformation et le maintien ou non d'un encadrement technique performant (vétérinaires, fournisseurs, conseils...).

c) La production laitière dans les zones de montagne et de piémont

Les exploitations laitières localisées dans les zones de montagne et de piémont sont, tout à la fois, plus spécialisées, plus herbagères, plus extensives et plus petites (quota moyen inférieur d'un tiers pour une main-d'œuvre à peine inférieure). Comme dans d'autres pays européens, elles disposent de moins de marges de manœuvre pour changer de production agricole ou réorienter les assolements. Dans ces zones, les contraintes qui pèsent sur le développement de la production laitière ont favorisé la diversification des activités et la recherche de valeur ajoutée, particulièrement via la production de fromages sous AOC. D'après les estimations du CNIEL, un tiers du lait produit en montagne est utilisé pour les fromages AOC et, d'après le recensement agricole 2010, $38 \%$ des exploitations de montagnepiémont relèvent d'une filière AOC (contre moins de 5\% en plaine). Moyennant l'existence de forts contrastes entre massifs, de nombreux exploitants ont également développé une diversification para-agricole (vente directe, tourisme...).

- Les exploitations laitières du Massif Central pèsent fortement dans la moyenne générale. Il s'agit, en effet, de la première zone laitière française de montagne avec $40 \%$ du nombre d'exploitations (et même près des deux tiers si l'on y intègre les zones de piémont). Ces exploitations, à $70 \%$ en statut individuel sans salarié, sont beaucoup plus petites et moins modernisées que dans les autres massifs ; un quart d'entre elles disposent d'un quota inférieur à 100000 litres de lait. Dans cette zone, la moitié des exploitations est encore imposée au régime TVA forfaitaire (contre 18\% dans le Jura et moins de $10 \%$ en plaine), mais le nombre d'exploitations au bénéfice réel a augmenté de 50\% depuis 2000. En 2010, 62\% des éleveurs de l'Ouest du Massif se déclaraient engagées dans une filière AOC (Cantal, Saint-nectaire) contre $8 \%$ dans la partie Est. Néanmoins la valorisation du lait accuse un fort décalage par rapport aux autres zones de montagne puisque, en moyenne, le prix du lait au producteur n'est pas supérieur à celui obtenu en plaine (Bour-Poitrinal et Tosi 2011). La transformation fromagère à la ferme est assez fréquente $(10 \%)$ dans la zone volcanique de l'Ouest du massif (Saint-Nectaire, première AOC fermière de France, Salers). Le massif se prête peu aux diversifications para et extra-agricoles qui y sont particulièrement rares pour une zone de montagne (Mundler 2010). En revanche, les diversifications agricoles (viande bovine) y sont plus fréquentes et traditionnelles: environ une exploitation sur deux à l'Ouest du massif, zone pédoclimatique favorable à la pousse de l'herbe durant toute la saison de pâturage et dans laquelle le recours aux estives est significatif.

- Dans le Jura, les exploitations laitières sont plus spécialisées, plus grandes (257 000 litres de quota laitier et 96 ha de SAU), plus fréquemment de forme sociétaire $(32 \%)$ et plus massivement engagées dans les filières AOC $(87 \%$ en Comté ou Mont-d'Or). La transformation du lait dans de petits ateliers coopératifs et le savoir-faire des acteurs de la filière (cahier des charges rigoureux, maîtrise technique du produit, stratégies commerciales...) procurent, depuis déjà de nombreuses années, une bonne valorisation du lait aux producteurs (Jeanneaux et al 2009). Ainsi, ceux-ci obtiennent de biens meilleurs revenus que dans le Massif Central et sont plus rarement enclins à exercer une activité para ou extra-agricole.

- Dans les Alpes du Nord (Savoie hors avant-pays et Isère), la dimension moyenne des exploitations laitières (192 000 litres de quota) est peu éloignée de la moyenne des zones de montagne (221 000 litres); la taille est cependant plus modeste (136000 litres) pour les 800 exploitations de haute-montagne. Dans cette zone, où la valorisation du lait atteint, sur certains segments, un niveau encore plus élevé qu'en Franche-Comté, la recherche de valeur ajoutée est très développée (Chatellier et Delattre 2003) :
$23 \%$ des exploitations transforment le lait à la ferme (Reblochon, Tome...); $59 \%$ des exploitations s'inscrivent dans une filière AOC (68\% en Savoie). Si les exploitations sont spécialisées en production laitière, elles sont aussi assez fréquemment diversifiées vers des activités para $(31 \%)$ ou extra-agricoles (un chef d'exploitation sur six est double actif). De même, près du tiers des exploitations utilisent des pâturages collectifs (alpages).

- Dans les Vosges, où la transformation fermière est fréquente $(23 \%)$, la dimension des exploitations est légèrement plus faible (201000 litres de quota par exploitation) que la moyenne nationale des zones de montagne. Les diversifications para-agricoles sont encore importantes (29\% vente directe-tourisme), même si elles tendent à reculer depuis quelques années. Concernant la maind'œuvre, $14 \%$ des exploitations emploient des salariés permanents (fermes auberges...) et $9 \%$ des chefs d'exploitation sont double-actifs.

- Les zones de « piémonts » (5 100 exploitations laitières) regroupent ici l'ensemble des petites régions de montagne où la culture du maïs ensilage (présent dans $78 \%$ des exploitations) a permis une intensification de la production (en moyenne 6600 litres de lait par vache et 1,3 UGB par ha). Il s'agit des monts du Lyonnais, des Ségalas, de la Chataigneraie, des piémonts pyrénéen et alpin. La dimension des exploitations est également intermédiaire (255000 litres de quota). Une exploitation sur trois a une diversification agricole (souvent en viande bovine). Les filières AOC, la transformation fermière, de même que les diversifications para ou extra-agricoles y sont peu présentes (moins de 10\%).

Dans les zones de montagne, où les difficultés de circulation augmentent fortement les coûts de collecte du lait, la densité de production laitière moyenne s'élève 50000 litres $/ \mathrm{km}^{2}$ (davantage pour le massif du Jura). Cette densité est deux à trois fois moins importante que celle observée dans les territoires de l'Ouest français (150 à 180000 litres/ $\mathrm{km}^{2}$ ), mais supérieure à celle des zones de polyculture-élevage concernées par la production laitière $\left(35000\right.$ litres $/ \mathrm{km}^{2}$ en moyenne). En montagne, les exploitations laitières forment un maillage serré (une exploitation pour $3,7 \mathrm{~km}^{2}$ d'après des calculs effectués sur l'exercice 2007, contre une pour $2 \mathrm{~km}^{2}$ en zone d'élevage de plaine et une pour $8 \mathrm{~km}^{2}$ en zone de polyculture-élevage). Leur présence et leurs activités sont essentielles pour l'équilibre socio-économique et environnemental de nombreuses zones. Cela est particulièrement le cas dans le Massif 
Central qui partage avec la Bretagne une forte dépendance de ses bassins de vie aux activités agricoles et agro-alimentaires, mais s'en distingue, d'après l'INSEE et la DATAR, par des évolutions démographiques plus souvent négatives (déficits naturel et migratoire).

Les systèmes laitiers de montagne, présentent les caractéristiques typiquement nécessaires au maintien des zones à Haute Valeur Naturelle définies par l'Agence Européenne pour l'Environnement (Pointereau 2010) : forte dominante de prairies naturelles, faible chargement animal, faible utilisation d'intrants chimiques et forte utilisation de main-d'œuvre agricole (systèmes intensifs en travail). D'après le Réseau d'Information Comptable Agricole (RICA), près des trois quarts des éleveurs de montagne-piémont bénéficient de mesures agro-environnementales (PHAE, CTE/ CAD, MAE) contre moins d'un quart en zone de plaine.

d) La production laitière dans des zones non laitières (ou plus marginales)

Ces zones regroupent, en 2010, 2800 exploitations laitières situées dans des zones à très faible densité : zone herbagère allaitante du Nord Massif Central, zones de montagne souvent ovines des Pyrénées centrales et orientales ou du Sud-Est du Massif Central, autres producteurs isolés en zones de plaine (périurbain). Ces situations, où la collecte du lait (ou sa pérennité) n'est pas toujours assurée, nécessitent souvent des stratégies de valorisation autonome de la production laitière. La production laitière y est certes menacée, mais ce ne sont pas les zones qui affichent les taux de restructuration les plus forts sur la période récente. Les producteurs désireux d'arrêter la production laitière l'ont souvent déjà fait.

\section{2 / Des écarts importants de productivité du travail et de résultats économiques}

Au-delà de la mise en évidence des spécificités propres à chaque zone précédemment étudiée, une analyse transversale permet de souligner l'existence d'écarts importants en termes de productivité du travail des exploitations laitières françaises (Charroin et al 2012). Ceux-ci sont encore plus nets lorsque les comparaisons sont établies avec les bassins concurrents de l'Europe du Nord (Institut de l'Elevage 2007, Chatellier et al 2009, Commission européenne 2012b). En France, les gains de productivité du travail s'accélèrent depuis quelques années : la production laitière par exploitation a progressé autant au cours des trois années 2007-2010 qu'elle ne l'avait fait au cours des années 2000-2007, le tout à main-d'œuvre constante. Ces gains de productivité ont permis, avec l'amélioration du prix du lait, l'obtention d'un revenu moyen 2011 parmi les plus élevés des quinze dernières années.

La productivité du travail dans les exploitations laitières est, en moyenne, élevée dans les zones de polycultureélevage. Les exploitations y produisent plus de lait que dans les zones d'élevage de plaine (361000 litres par an contre 351000 litres en 2010) alors que ce n'était pas le cas en 2000 (207 000 litres contre 212000 litres), plus de cultures de vente ( 58 contre 24 ha), avec un cheptel global à peine inférieur (99 UGB contre 104 UGB). Par emploi agricole (exprimé en UTA), la production laitière est à peine inférieure à celle obtenue en zone d'élevage de plaine (5\%). Toutes les comparaisons réalisées depuis quelques années montrent les très bons résultats de ces exploitations françaises de polyculture-élevage laitier qui rivalisent avec les unités spécialisées les plus productives et les plus efficaces d'Europe du Nord.

A contrario, les exploitations de montagne, pourtant plus spécialisées, font face à des handicaps naturels qui limitent fortement la productivité de la maind'œuvre (114 000 litres par UTA contre 171000 litres en zone de polycultureélevage et 162000 litres en zone de plaine). La productivité est également plus modeste lorsqu'elle est exprimée à l'unité de surface $(0,99 \mathrm{UGB} /$ ha contre 1,58 et $1,61 \mathrm{UGB} /$ ha respectivement) ou à la vache laitière (5 800 litres par an contre 6500 et 7100 litres respectivement). La dimension brute des exploitations françaises de montagne (76 ha SAU, 38 vaches laitières et $220000 \mathrm{~L}$ de quota) est cependant plus importante que leurs homologues de la plupart des autres pays européens (Institut de l'Elevage 2009a) et, aussi, plus proche de leurs consœurs de plaine (90 ha, 54 vaches laitières et $360000 \mathrm{~L}$ de quota pour les zones d'élevage). La sanction économique de ces écarts de productivité physique du travail est variable selon les massifs. S'ils sont souvent compensés, suivant les années, par une forte valeur ajoutée dans les montagnes de l'Est grâce aux filières fromagères en AOC, ce n'est pas le cas dans le Massif Central où le taux de valeur ajoutée est inférieur à celui des zones de plaine, en particulier dans les périodes de sécheresse. Le positionnement des exploitations de montagne, en retrait sur tous les critères économiques (en moyenne), masque donc une hétérogénéité intermassifs et une situation plus difficile dans le Massif Central. Les exploitations, plus petites et plus tardivement entrées dans une phase de modernisation et d'investissements, dégagent une valeur ajoutée souvent modeste.
Dans les zones d'élevage de plaine, les exploitations dites spécialisées ont cherché à valoriser un quota limité, via une bonne maîtrise des charges opérationnelles. Cela est particulièrement vrai dans l'Ouest, où l'intensification de la production laitière permet de libérer des surfaces pour les cultures de vente et les autres productions animales (viande bovine, porcs, volailles). Jusqu'en 2006, ces exploitations ont connu une évolution gourmande en capital au regard de leurs gains de productivité du travail (lesquels sont deux fois plus faibles que dans les autres grands pays laitiers européens). Cela tient principalement aux investissements, parfois importants, réalisés d'une part, pour respecter les normes environnementales (dans le cadre notamment du Programme de Maîtrise de la Pollution d'Origine Agricole - PMPOA) et, d'autre part, pour mieux gérer la contrainte de travail ressentie. Durant cette période, le coût de production du lait, au demeurant encore assez hétérogène entre exploitations et systèmes techniques (Garambois et al 2012), a ainsi été poussé à la hausse par des charges fixes peu diluées. Cette structure de coût suggérait aussi que ces élevages s'étaient modernisés et étaient, pour une part non négligeable d'entre eux, capables de produire demain plus de lait à couts fixes constants (Lelyon et al 2012). C'est ce qui a été constaté en 2007-2008 et surtout après la crise de 2009 . La hausse de production particulièrement forte dans les grandes exploitations de plaine $(+29 \%$ en Bretagne entre 2009 et 2011) a permis d'augmenter le taux d'utilisation des équipements disponibles et a provoqué l'apparition d'économies d'échelle apparentes au profit des plus grands ateliers (Perrot et al 2012). Le niveau de saturation actuel des équipements est assez mal connu et ce phénomène pourrait s'estomper si une nouvelle phase d'investissements importants s'avérait nécessaire pour absorber la restructuration des exploitations qui se poursuivra, notamment pour des raisons démographiques.

\section{3 / Une main-d'œuvre surtout familiale, mais des dynamiques démographiques contrastées}

Contrairement à la plupart des caractéristiques présentées jusqu'ici (orientation des systèmes d'exploitation, dimension, niveau d'intensification, résultats économiques), les formes d'organisation du travail et les caractéristiques démographiques des chefs d'exploitation diffèrent finalement encore assez peu d'une zone géographique à l'autre. Parmi les exploitations laitières françaises, différentes formes d'organisation de la maind'œuvre, plus ou moins complexes et laissant une place plus ou moins grande à la seule sphère familiale (Dufour et Giraud 
2012), peuvent être distinguées à partir du Recensement agricole de 2010.

Près des deux tiers des exploitations laitières françaises sont de type individuel (en incluant ici les EARL unipersonnelles ou entre époux). Les exploitations qui n'ont pas de salarié permanent et qui sont de plus en plus souvent gérées par une personne seule (le conjoint ne participant désormais aux travaux que dans $52 \%$ de ces cas) représentent encore $57 \%$ de l'ensemble des exploitations laitières françaises. Un peu moins du tiers des exploitations laitières françaises relève des formes sociétaires (à l'exclusion des EARL unipersonnelles ou entre époux, classées en unité individuelle). De manière plus précise, les sociétés familiales avec des associés tous apparentés, mais de générations différentes (typiques des formes préconisées pour la transmission des exploitations de type GAEC père-fils), représentent $11 \%$ du total des exploitations laitières ; les sociétés familiales avec des associés tous apparentés avec au moins deux collatéraux de même génération (frères/sœurs, cousin(e)s) couvrent $14 \%$ des effectifs ; les sociétés non familiales (tous les associés ne sont pas apparentés) représentent $6 \%$ des effectifs. Les exploitations non répertoriés ci-dessus ( $2 \%$ des effectifs) correspondent à des exploitations à temps partiel qui mobilisent au total moins d'une UTA (ces exploitations sont rares dans toutes les zones).

Les contrastes entre zones géographiques sont globalement assez modérés. Plus que la montagne, c'est le Massif Central (et ses piémonts) qui se distingue par la rareté des exploitations individuelles avec salariés ou des sociétés non familiales. Dans les massifs du Jura et des Alpes du Nord, le poids des formes sociétaires est important, à peu près autant que dans les zones de polyculture-élevage qui, elles, présentent davantage d'exploitations individuelles avec salariés (jusqu'à 15\%). Ces dernières formes sont également présentes dans le massif des Vosges et dans certaines zones d'élevage de plaine, sauf dans l'Ouest où les sociétés non familiales sont les plus répandues (autant que dans la zone de polyculture-élevage à contrainte herbagère - exploitations de grande dimension de l'Est de la France). Ces différentes formes d'organisation du travail renvoient à des exploitations et à des ateliers laitiers de taille différente. Les exploitations disposant de moins de 300000 litres de quota couvrent $52 \%$ des effectifs totaux : $17 \%$ des sociétés et $88 \%$ des exploitations individuelles. A l'autre extrême, les exploitations qui gèrent plus de 600000 litres de quota couvrent $8 \%$ des effectifs totaux, $36 \%$ des sociétés familiales entre collatéraux et $31 \%$ des sociétés non familiales.
Figure 6. L'évolution des livraisons de lait de vache en France entre 1980 et 2011 (indice $100=\max 1983-86$ ).

Source : Enquêtes laitières annuelles / Traitement Institut de l'Elevage.

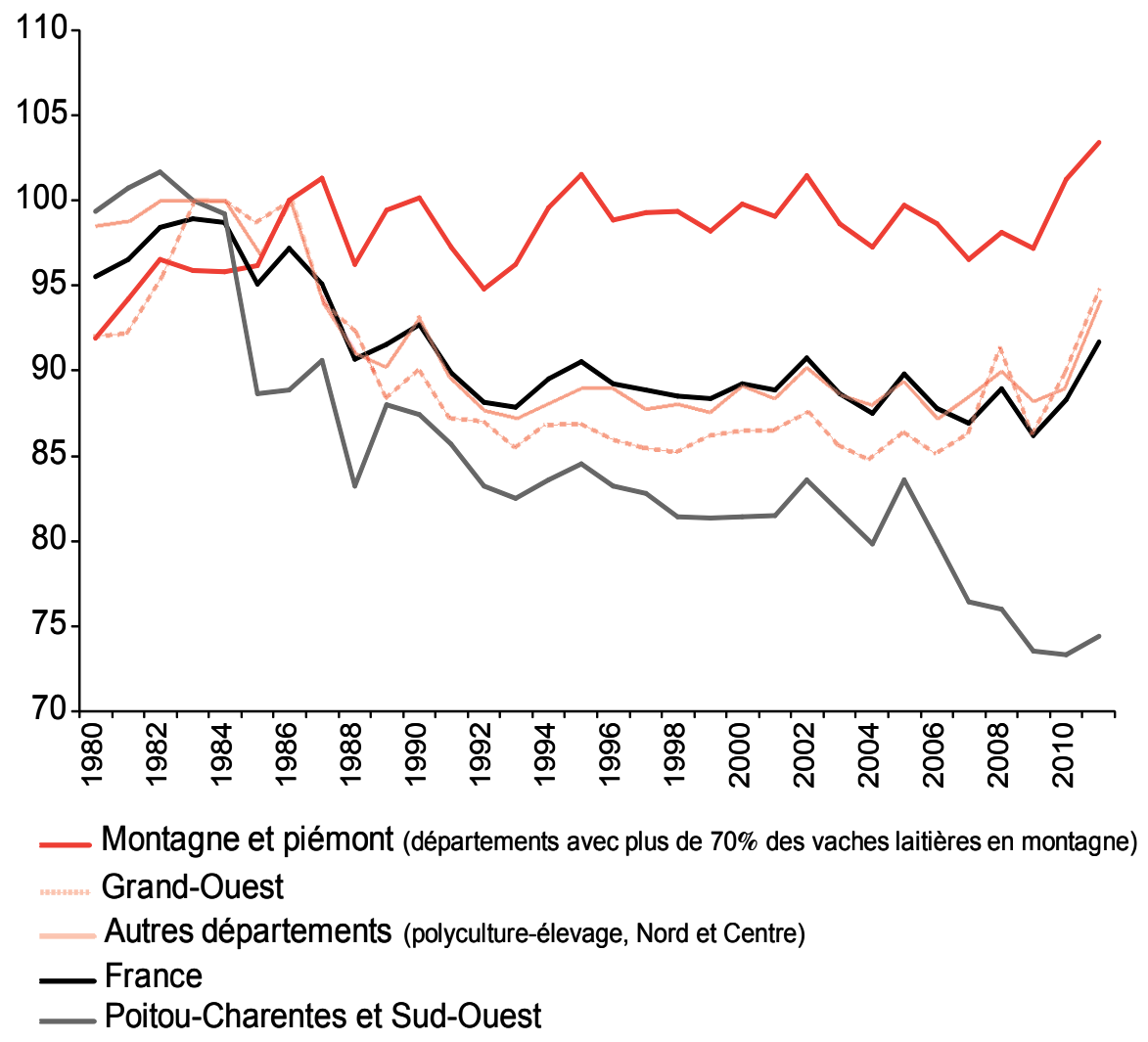

La situation démographique, appréciée à partir de l'âge des chefs d'exploitation, est encore moins différente d'une zone à l'autre. Un peu moins du quart des chefs d'exploitation avait moins de 40 ans en 2010, à peine plus en comptant tous les co-exploitants, et $20 \%$ avaient plus de 55 ans (11\% sans successeur connu). Ce sont des résultats approximativement identiques dans les trois grandes zones étudiées, avec cependant un léger avantage à la jeunesse dans les zones de polyculture-élevage où les formes sociétaires sont plus représentées (or, à responsabilité égale, c'est le plus jeune coexploitant qui est retenu dans le calcul). Seul le massif du Jura se distingue de façon très nette, tant au niveau des chefs de moins de 40 ans $(30 \%)$ que de ceux de plus de 55 ans $(16 \%)$ en raison du poids des formes sociétaires et d'une dynamique d'installation exceptionnelle. Dans les Alpes du Nord, le taux de chefs de plus de 55 ans est plus élevé (26 dont 16\% sans successeur).

Le taux de remplacement des départs à la retraite est nettement meilleur en montagne qu'en plaine et, plus encore, dans les zones de polyculture-élevage, où les livraisons de lait ont aussi reculé davantage (figure 6). Une représentation graphique croisant, en moyenne pour la période 2000 à 2010 , le taux de remplacement des exploitations laitières avec l'évolution de leur nombre permet d'en rendre compte (figure 7). Ainsi, par exemple, la restructuration a été nettement plus faible dans le Jura (une installation pour 2,2 départs et - 2,4\% d'exploitations par an) que dans les zones de polycultureélevage à faible densité et du Sud-Ouest (une installation pour 6,5 départs et - 6,5\% d'exploitations par an). Dans ces deux dernières zones, la vitesse de restructuration est moins liée à une origine démographique qu'aux possibilités de reconversion, qui sont d'autant plus encouragées que le prix des céréales est élevé et les aides sont découplées (Lelyon et al 2011). varié de façon très importante depuis 2006. Après un rebond en 2007 et surtout en 2008 suite à l'embellie sur les marchés laitiers, un effondrement a été constaté en 2009 pendant la crise. Depuis 2010, un certain redémarrage est constaté. Du fait de l'abondance des installations dans le secteur laitier entre 1980 et 1990, la fin des quotas laitiers sera gérée, pour une part importante, par des éleveurs en fin de carrière (Perrot 2010). Il s'agit là d'un enjeu important, ce d'autant que les nouvelles générations expriment leurs attentes en matière d'amélioration des conditions d'exercice de ce métier.
En France, le nombre d'installations a 
Figure 7. Le taux de remplacement des départs et la restructuration laitière par zone (moyenne 2000-2010).

Source : Agreste - Recensements agricoles 2000-2010 / Traitement Institut de l'Elevage.

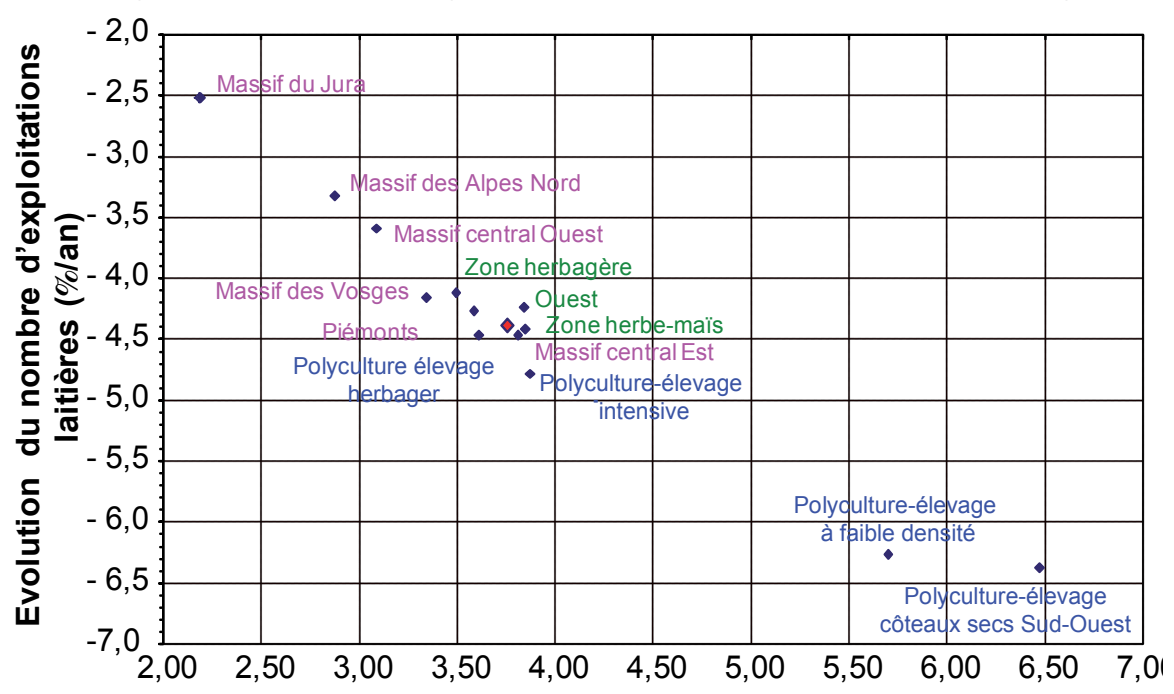

1 installation (chef ou coexploitant hors conjoint au moins 10 ans plus jeune que le chef) pour $n$ départs

\section{3 / Des quotas laitiers aux contrats : entre craintes et espoirs}

Le secteur laitier français est riche de sa diversité (productive et territoriale) et développe progressivement ses exportations. Néanmoins, de nombreuses questions se posent quant à son avenir du fait de la concurrence de plusieurs pays européens, de la décroissance rapide du nombre d'exploitations, de l'augmentation des coûts de production et des contraintes environnementales qui pèsent de plus en plus sur le développement de l'offre. Cela est d'autant plus le cas que la fin des quotas laitiers pourrait conduire à une croissance déraisonnable de la production européenne de lait et, par voie de conséquence, à une pression à la baisse sur le prix du lait payé au producteur. Après la suppression des quotas laitiers en 2015, l'ajustement de l'offre à la demande ne sera plus arbitré par des règles administratives strictes fixées par les pouvoirs publics, mais par les entreprises de la transformation au travers d'un système de contractualisation. Ce passage d'une régulation publique à une régulation privée n'est évidemment pas neutre sur la manière dont le secteur laitier français évoluera. Après la mise en œuvre de mesures transitoires à l'échelle de l'UE et de la France pour préparer le secteur à la fin des quotas laitiers, de nouveaux modes de gestion de l'offre verront le jour. Quelles que soient les mesures adoptées pour relier les producteurs aux acteurs de la transformation, la fin des quotas laitiers modifiera les rapports de la concurrence (Dervillé et al 2012).

\section{1 / Les mesures transitoires prises par anticipation de l'aban- don des quotas}

Pour se préparer à l'échéance de 2015, les autorités communautaires et françaises ont adopté plusieurs mesures visant à favoriser une transition en « douceur » vers un nouveau régime de gestion de l'offre.

\section{a) Les mesures prises à l'échelle européenne}

La Commission européenne a adopté, dans le cadre du bilan de santé de la PAC, le mécanisme dit du "soft landing" (atterrissage en douceur). Celui-ci prévoit une augmentation du droit à produire attribué à chaque Etat membre à raison de $+1 \%$ par an entre 2009 et 2015 . L'objectif est, d'une part, de rendre le système des quotas laitiers progressivement moins contraignant (voire inopérant) et, d'autre part, de favoriser une baisse de la valeur marchande des droits à produire dans les pays où un marché de ces droits existe (dont les Pays-Bas, le Danemark et l'Allemagne). D'après des travaux de modélisation (BouamraMechemache et al 2009), une augmentation de $7 \%$ du quota laitier communautaire suffirait à saturer les capacités de production des producteurs laitiers et conduire à une nullité de la valeur d'échange des quotas laitiers. Depuis 2009 , et pour des raisons diverses (conditions climatiques, volatilité des prix, trop grande rigidité dans les réallocations de droits à produire entre exploitations...), les livraisons européennes de lait ont été inférieures à la référence autorisée (LEI 2011), laquelle a cependant été fixée à un niveau global supérieur aux capaci- tés d'écoulement sur les marchés. Si la sous-réalisation du quota laitier a été, en France, très importante lors de la crise de 2009 , l'écart tend à se resserrer en 2011 et 2012 .

Les mesures adoptées dans le cadre du « paquet lait» (Commission européenne 2010) visent, du moins théoriquement, à donner plus de poids aux producteurs dans leurs négociations avec les industriels. Ainsi, les producteurs auront la possibilité de se regrouper en Organisations de Producteurs (OP), à la condition cependant que celles-ci ne représentent pas plus de $3,5 \%$ de la production de l'ensemble des pays de l'UE ou le tiers de la production nationale. En outre, la Commission recommande la mise en œuvre de contrats écrits de livraison de lait entre les producteurs et les collecteurs de façon à donner plus de visibilité aux deux acteurs. Ces contrats doivent comprendre les éléments suivants : la durée de l'engagement, le volume et le calendrier des livraisons, et le prix (fixe ou variable en fonction de facteurs établis dans le contrat). Les producteurs de lait livrant leur lait à leur propre coopérative de transformation (un peu moins de $60 \%$ du lait européen) ne sont pas tenus de conclure des contrats.

En permettant une dérogation aux règles de la libre concurrence inscrites dans le paquet lait, les autorités communautaires ont, par ailleurs, accepté de prendre en compte les spécificités des filières fromagères bénéficiant $d$ 'une Appellation d'Origine Protégée (AOP) ou d'une Indication Géographique Protégée (IGP). Ces dernières peuvent désormais élaborer des plans de maîtrise des volumes de leurs fabrications fromagères, sous certaines conditions. Elles peuvent se structurer en interprofessions ou en Organismes de Défense et de Gestion (ODG). Jusqu'ici, un arrêté français permettait aux fromages à pâtes pressées cuites, comme le Comté ou le Beaufort, de mettre en place des plans de maîtrise des volumes ; cette dérogation a été transposée au niveau européen et pourra donc être élargie à d'autres fromages sous AOP ou IGP. Pour être acceptée au niveau européen pour une période de trois années renouvelables, la régulation doit avoir un impact se limitant uniquement au produit concerné par l'AOP et la filière doit s'engager à rester ouverte à l'arrivée de nouveaux éleveurs laitiers potentiels.

\section{b) Les mesures prises en France}

Au niveau français, les pouvoirs publics ont, tout d'abord, adopté, dès 2007, une mesure appelée " transferts de quota spécifique sans terre (TSST) ». Selon une logique contraire à celle qui prévalait jusqu'alors (gratuité des droits à produire 
et lien fort entre le quota laitier et le foncier), le dispositif permet d'effectuer des transferts de quotas laitiers sans cession de terre contre le paiement par les producteurs bénéficiaires de ces quotas d'une somme $(0,1125$ euro par litre pour la campagne 2011-2012, ce taux étant ensuite dégressif jusqu'à la suppression des quotas). Il est ouvert dans la limite des quantités de références laitières libérées au titre des indemnités à l'abandon total ou partiel de la production laitière ( « cessations primées » ou " aide à la cessation d'activité laitière (ACAL) ».

Le Ministère français en charge de l'agriculture a ensuite incité les acteurs de la filière laitière à structurer davantage leurs relations sous une forme contractuelle. Ainsi, un décret, publié en décembre 2010 (MAAPRAT 2010), contraint les industriels laitiers à fournir à leurs fournisseurs (les producteurs) une proposition de contrat écrit à compter du $1^{\text {er }}$ avril 2011. Ce contrat, d'une durée minimale de 5 ans, doit préciser les volumes de lait à livrer pour chacune des périodes de douze mois (le cas échéant avec des volumes par sous-périodes) et définir les conditions dans lesquelles le volume prévu peut être ajusté. Outre la définition des caractéristiques du lait à livrer, il doit également mentionner les règles applicables lorsque le producteur dépasse ou n'atteint pas les volumes attendus. Le contrat fixe également les modalités de la collecte, les critères et les références pris en compte pour la détermination du prix de base du lait, ainsi que les modalités de facturation et de paiement du lait. Enfin, ce contrat doit faire état des modalités de révision ou de résiliation par l'une ou l'autre des parties.

Les pouvoirs publics français ont également révisé, pour la période 2011 à 2015 , le maillage géographique de référence pour la gestion des quotas laitiers (MAAPRAT 2011). Celle-ci ne se fait plus à l'échelle de chaque département, mais au niveau de neuf grands bassins de production (cf. les limites mentionnées sur la carte 1). Ainsi, grâce à la mutualisation des références laitières disponibles, un éleveur peut désormais se voir attribué du quota issu d'un département voisin faisant partie du même bassin laitier.

\section{2 / Les futures stratégies d'ap- provisionnement en lait des indus- triels}

Une enquête menée par l'Institut de l'Elevage et sept Chambres d'Agriculture auprès des principaux transformateurs laitiers français (privés et coopératives) a permis d'identifier les principales stratégies d'approvisionnement en lait envisagées pour la période post 2015 (Institut de l'Elevage 2011). Il en ressort, tout d'abord, que quatre facteurs princi- paux influencent le positionnement des entreprises.

- Les caractéristiques du bassin de collecte et le potentiel de développement de la production après 2015. Selon la zone considérée (zones d'élevage dense de plaine, zone de polyculture-élevage ou zone de montagne), les industriels laitiers n'envisagent pas leurs approvisionnements futurs de façon identique.

- Le lien des entreprises à leur territoire de collecte. Celui-ci est très fort pour les entreprises, privées ou coopératives, qui transforment du lait sous signe de qualité AOP. Pour les coopératives laitières de petite ou moyenne taille, dont les « sociétaires » sont les livreurs, ce lien est consubstantiel à leur existence. En revanche, il est plus ténu dans les grands groupes privés nationaux et internationaux, implantés dans de multiples régions et dont le bassin de collecte est un agrégat de zones de collecte.

- L'éventail des fabrications des transformateurs (ou mix-produit). Les industriels spécialisés dans les produits frais ont des attentes et des exigences différentes de celles des fromagers, des fabricants d'ingrédients laitiers ou des entités plus généralistes présentes dans toutes les familles de produits. Pour les premiers, la réduction de la saisonnalité apparaît comme un axe majeur. Pour les fabricants de fromages de garde et les fabricants généralistes, la saisonnalité semble moins problématique que l'ajustement de la collecte annuelle aux débouchés.

- Le niveau d'utilisation des outils de transformation. La stratégie d'approvisionnement d'un transformateur sera différente s'il est dans l'obligation d'investir dans des capacités de transformation supplémentaires pour traiter les volumes additionnels, ou si ses installations actuelles lui permettent de faire face à une hausse de la collecte.

Cette enquête sur la fin programmée des quotas laitiers met en lumière le fait que le statut de l'entreprise (coopérative vs privée) interfère sur les options privilégiées relativement à la gestion des volumes. Ainsi, deux stratégies distinctes sont envisagées, à savoir celle dite « d'accompagnement de l'offre » et celle dite « d'encadrement des livraisons ».

\section{a) L'accompagnement de l'offre}

Les coopératives et les groupes à capitaux coopératifs s'inscrivent dans une logique d'accompagnement de l'offre laitière. Ils doivent statutairement collecter, transformer et valoriser tout le lait de leurs adhérents sans discrimination entre eux. Cette logique se décline cependant de manière différente selon le potentiel laitier du bassin. Ainsi, dans les bassins à haut potentiel, notamment ceux du Grand-Ouest et du Nord de la France les coopératives laitières se préparent à une progression de leur collecte à compter de 2015 (contrairement à celles localisées dans les zones défavorisées du Massif Central ou dans les zones à faible densité de polyculture-élevage). Le principal enjeu consistera alors à permettre aux éleveurs qui le peuvent et qui le souhaitent d'augmenter leur production en valorisant au mieux les volumes supplémentaires.

Pour répondre à ce double défi, les entreprises proposent de mettre en place un contrat à volumes et prix différenciés, dit également contrat « double volume / double prix ». Dans ce schéma, un volume «A » serait attribué aux producteurs sur la base de tout ou partie du quota historique et bénéficierait du prix d'équilibre constaté sur le marché intérieur (prix « $A$ ») ; un volume « $\mathrm{B} »$, additionnel et facultatif, pourrait être accordé aux producteurs, mais pour un niveau de prix plus variable (prix « $\mathrm{B} »)$, correspondant à la valorisation du lait en produits industriels (beurre et poudre). Un tel dispositif pourrait permettre aux industriels de devenir plus réactifs et plus compétitifs sur des marchés concurrentiels (produits à faible valeur ajoutée ou marchés d'exports).

\section{b) L'encadrement des livraisons}

L'option des prix différenciés est critiquée par certains acteurs, surtout ceux issus du privé. Ils considèrent, en effet, qu'un tel système est difficilement applicable en raison de la difficulté technique de procéder à une segmentation efficace entre les volumes « $A$ » et $\langle\mathrm{B}\rangle$; le problème de l'étanchéité peut inciter à des fraudes. De plus, ils redoutent que les centrales d'achat fassent pression à la baisse sur les prix issus du volume « A ». Ils soulignent aussi le fait que ce système entraînerait une perte de compétitivité à long terme de la filière. Au travers de cette option, les entreprises ont, en effet, la possibilité de reporter aux producteurs leurs propres défaillances en termes d'innovations et de structure de coûts.

A quelques exceptions près, les entreprises privées s'inscrivent donc dans une logique plus prononcée d'encadrement de l'offre. L'esprit qui prévaut est que les livraisons doivent être adaptées à la capacité de valorisation des produits transformés sur les marchés (dans un contexte où ceux-ci sont devenus plus mâtures tant au niveau national qu'européen). Dans ce cadre, les éleveurs sont considérés comme des fournisseurs d'une matière première (le lait), et les 
relations avec le transformateur s'opèreront principalement au sein de l'OP. Les entreprises privées possédant un mixproduit étendu proposent majoritairement de substituer le quota administratif par un contrat commercial. Le producteur disposerait d'un volume de lait contractuel à produire au cours de l'année, sans contrainte forte sur la saisonnalité de la production. Ce volume pourrait être revu à la hausse ou à la baisse d'une année sur l'autre en fonction de l'évolution des débouchés de l'entreprise. Tout dépassement de la référence serait sanctionné par des pénalités financières dissuasives, voire par un arrêt temporaire de collecte.

Les entreprises ayant un positionnement axé sur les fromages de garde ou les produits laitiers frais souhaitent collecter un volume de lait qui soit au plus près de leurs besoins. Tout en continuant à créer de la valeur ajoutée au travers de leurs stratégies de marques commerciales, ces entreprises déplorent l'existence d'une saisonnalité trop marquée de la collecte ; cette dernière génère des excédents d'offre au printemps et, à l'inverse, est source de tensions durant les mois d'été. Ces entreprises concernées chercheront, au travers des contrats, à contenir l'offre et à lisser la production tout au long de l'année. Ces contrats seront donc susceptibles d'influencer les éleveurs dans le sens d'une modification de leur système de production (période de vêlage, modèle alimentaire, assolement...). Pour donner plus de flexibilité, la question de la saisonnalité pourrait cependant être gérée à l'échelle d'une OP et non pas au niveau de chaque éleveur.

Grâce au principe de la contractualisation, les industriels laitiers disposeront de trois leviers pour gérer l'offre de lait et accompagner leurs démarches stratégiques. Le premier, commun à toutes les entreprises, est l'instauration d'un volume contractuel annuel qui se substituera aux actuels quotas laitiers. Cette référence annuelle qui s'apparente à un quota s'annonce très contraignante pour les éleveurs qui subiront des pénalités ou des refus de collecte au-delà de ce seuil. Elle sera plutôt discriminante pour les adhérents de coopératives qui comptent mettre en œuvre un prix du lait différent au-delà de ce seuil de livraisons. Le deuxième concerne la gestion de la saisonnalité qui s'annonce plus ou moins encadrée selon les entreprises. Le troisième concerne la gestion des références laitières libérées par les cessations laitières, lesquelles seront probablement plus conséquentes dans les bassins à faible potentiel.

L'instauration de contrats entre les producteurs de lait et les industriels est nécessaire pour clarifier les relations existantes et permettre aux différentes par- ties de bénéficier d'une visibilité à moyen terme (Rio 2012). Il faut cependant rappeler que les futurs contrats ne mentionneront pas le niveau de prix que les producteurs de lait obtiendront au cours de la période considérée. Le prix moyen dépendra donc d'abord, comme pour les autres produits agricoles, du positionnement produits/marché du transformateur, mais aussi de l'équilibre général entre l'offre et la demande. Les principaux enjeux de la négociation entre les représentants des producteurs et les industriels porteront sur les points suivants : la planification de la production (à l'échelle individuelle ou collective) et les pénalités liées en cas de non-respect; les modalités de transmission d'un contrat d'un agriculteur à un autre; le transfert de propriété du lait à une OP chargée de négocier collectivement le prix du lait; et la mise en place ou non de contrat collectifs. Dans les coopératives, le principal enjeu portera sur l'adaptation des modalités de rémunération du lait produit en volume " $\mathrm{A}$ 》 et 《 $\mathrm{B}$ » à un contexte laitier de plus en plus incertain et volatil.

\section{3 / Quelles stratégies et quel devenir pour les territoires lai- tiers?}

Dès le début des années quatre-vingtdix, un premier bilan des quotas laitiers, réalisé dans le cadre des activités du Sénat, affirmait : «Les quotas laitiers ont incontestablement cassé l'élan des régions dont la production progressait rapidement avant 1984 et permis à celles qui étaient engagées sur la voie du déclin de maintenir un minimum d'activité laitière" (Sénat 1992). Trois ans avant la fin programmée des quotas laitiers, cette phrase résonne encore et incite à réfléchir autour des trois questions suivantes :

- Une autre voie de régulation du secteur aurait-elle été plus adaptée au cas français et finalement préférable sur les plans sociaux, territoriaux, environnementaux et budgétaires? Répondre à cette question suppose non seulement d'analyser en quoi d'autres alternatives étaient potentiellement applicables dans le contexte de l'époque, mais surtout d'imaginer ce qu'auraient été les adaptations apportées aux dispositifs initialement retenus (Hairy et al 1983, Butault et al 1984, Gouin 2005). Si les quotas n'ont pas permis d'enrayer la baisse du nombre des exploitations (baisse qui aurait été probablement plus forte dans l'hypothèse d'une adaptation de l'offre par la baisse des prix), ils ont favorisé une meilleure maîtrise des dépenses budgétaires et, du moins en France, freiné le processus de concentration géographique de la production. Les quotas laitiers ont, avec les autres mécanismes de soutien (prix garantis, restitutions aux exporta- tions, droits de douanes...) adoptés dans le cadre de la PAC (Chatellier 2010, Gohin 2012), assuré une protection aux bénéficiaires des droits à produire et aux entreprises de la transformation.

- Les quotas laitiers ont-ils bloqué pendant trente années l'expression des avantages comparatifs? En figeant administrativement la production laitière entre les Etats membres, les quotas ont clairement constitué un frein aux processus économiques classiques conduisant à une concentration de l'offre dans les pays/ zones bénéficiant d'atouts en termes de coûts de production. Ainsi, la répartition de l'offre laitière entre les pays de l'UE et les bassins de production serait probablement différente aujourd'hui si d'autres options de régulation avaient été privilégiées. Pour autant, la compétitivité actuelle du secteur ne peut être attribuée aux seules modalités de régulation de l'offre. En bloquant les volumes de production sur un territoire donné, les quotas laitiers ont aussi encouragé les acteurs à imaginer d'autres voies d'adaptation, porteuses de valeur ajoutée : la diversification des productions agricoles pour valoriser les surfaces rendues disponibles par la maîtrise de l'offre et l'amélioration des performances zootechniques ; le développement des filières fromagères de qualité dans les zones défavorisées ; la diversification des formes d'utilisation du lait pour capter de nouveaux marchés, etc.

- La sortie des quotas laitiers sera-t-elle synonyme de dégel, la sortie progressive permettant déjà aux régions évoquées de reprendre leur "élan », tandis que d'autres ont de plus en plus de difficultés à maintenir un minimum d'activité laitière? A cette question précise, il est difficile de ne pas répondre, au moins en partie, de manière positive. L'évolution récente des livraisons régionales de lait d'une campagne sur l'autre, les taux de réalisation des quotas laitiers, le glissement observé des références laitières depuis que de nouvelles latitudes existent tendent à valider cette affirmation. Tout semble confirmer que des dynamiques laitières différentes sont à l'œuvre d'une région française à l'autre, renforçant, comme cela était prévisible, les contrastes régionaux au sein de la France laitière (Institut de l'Elevage 2009b).

Les dynamiques constatées dans la filière laitière ne tiennent pas uniquement à des déterminants propres au secteur (prix du lait, modalités de gestion des quotas...). Ainsi, dans les zones de polyculture-élevage peu denses en production laitière, les hausses de prix du lait observées en 2007-2008 et depuis la mi-2010 n'ont pas eu d'impacts significatifs sur le comportement des acteurs, contrairement à ce qui a été observé dans la plupart des autres régions. De même, 
ces zones sont marquées par une restructuration des d'exploitations qui va bien au-delà du simple effet de la démographie des chefs d'exploitation. De nombreuses exploitations, répondant aux signaux du marché, arbitrent entre différentes productions agricoles, au profit principalement des végétaux (grandes cultures) dès lors que le rapport entre les surfaces disponibles et la main-d'œuvre à rémunérer le permet. Ce phénomène est très net dans les zones où « l'ambiance laitière » se délite au travers d'une raréfaction des prestataires de services spécifiques compétents en production laitière (vétérinaires, conseillers...), d'une réduction des possibilités de travail en commun et d'échanges avec des éleveurs voisins, d'une exacerbation des contraintes ressenties liées à l'astreinte de la production. La densité de production et son évolution modifie donc les pouvoirs de marché entre les différents maillons de la filière.

L'histoire de la polyculture-élevage au sein de la France laitière est plutôt paradoxale. Cette association entre cultures et élevage s'est nettement mieux maintenue que chez nos voisins européens, grâce à la politique laitière française qui a ancré la production aux territoires et favorisé les croissances individuelles des exploitations situées dans des zones où les alternatives étaient possibles et attractives. Néanmoins, et comme l'ont bien perçu les acteurs industriels, la taille conséquente des ateliers laitiers de ces exploitations ne constitue pas une assurance contre leur non reconversion future vers d'autres productions agricoles. Partant de là, et sachant que les quotas laitiers vont disparaître, de nombreux industriels doutent aujourd'hui de l'opportunité de réinvestir dans certaines de ces zones. Les stratégies qui sont et seront adoptées sont susceptibles de fragiliser l'ensemble des filières territorialisées, y compris l'amont, dans une période où les potentiels avantages économiques et environnementaux de ces modes de production en polycultureélevage sont de plus en plus mis en avant (Chatellier et Dupraz 2011, Perrot et al 2012). Au demeurant, cette reconnaissance demeure encore discutée dans la mesure où la majorité des exploitations diversifiées est loin de suivre (pour des raisons économiques) le fonctionnement agronomique considéré, du moins théoriquement, comme idéal en termes de rotations, de fertilité, d'autonomie, etc.

Les zones de montagne constituent l'autre territoire où la fin des quotas risque de modifier en profondeur les équilibres, parfois fragiles, atteints grâce à des politiques de discrimination positive, notamment dans la première phase d'application des quotas laitiers (Prost 1986, Bazin 1999). La France est, rappe- lons-le, le premier pays européen producteur de lait de montagne. Les enjeux environnementaux, économiques, sociaux et territoriaux du maintien de filières laitières prospères dans ces zones sont particulièrement élevés. L'écart des tailles d'atelier est d'ores et déjà en train de s'amplifier entre la plaine et la montagne, ce qui devrait encore accroître les écarts de coût de production et de productivité du travail. La confrontation frontale avec les zones de plaine sur les productions de masse ne pourrait avoir que des effets très défavorables. Ces zones n'ont pas toutes réussi leur stratégie de démarcation. Les exemples étrangers, tout particulièrement italiens, montrent que des marges de progrès existent en matière de différenciation qualitative, mais aussi d'innovations en termes de gammes de produits, de stratégies de commercialisation et de circuits de distribution (Institut de l'Elevage 2009b). Néanmoins la mobilisation des ressources matérielles et immatérielles de ces filières de montagne ne suffira pas. Dans le cadre de la future PAC en cours de négociation (Commission européenne 2011a et b), elle devra être soutenue par un accompagnement politique spécifique et renouvelé : politique de compensation des handicaps ; aides aux investissements et à la modernisation ; rémunération accrue de la production de biens publics.

Même si les exploitations laitières des zones de polyculture-élevage sont individuellement souvent compétitives et particulièrement rentables (au niveau du revenu), ce sont surtout les unités plutôt spécialisées des bassins laitiers traditionnels de plaine, dont celles du GrandOuest (bassin qui représente la moitié de la production nationale), qui permettent à la France de ne pas trop souffrir d'un déficit de compétitivité au sein du marché communautaire (Perrot et al 2011). Dans un cadre économique qui deviendra fatalement plus concurrentiel, et tout en intégrant les limites imposées par les règles environnementales, les producteurs de lait de ces zones ont pris conscience de leurs avantages comparatifs. Ils disposent, en effet, d'un potentiel fourrager réel tant au niveau de l'herbe que du maïs ensilage (atouts climatique et agronomique), d'une réserve importante de productivité (comme ils l'ont démontré à plusieurs reprises au cours des dernières années), d'un coût modéré d'acquisition des facteurs de production (foncier et quotas) relativement à d'autres pays européens, d'un savoirfaire, spécifique et organisé, des acteurs de l'amont (fournisseurs des exploitations), de la présence d'opérateurs d'aval innovants et puissants, dont certains de dimension internationale.

Si l'objectif politique est de donner toutes leurs chances à chacune des trois grandes zones évoquées, il convient de prendre davantage en compte la diversité territoriale et d'anticiper les évolutions pour recomposer des filières stabilisées en zone de polyculture-élevage ; renforcer les politiques agricoles nationales et européennes en faveur des zones de montagne ; favoriser, dans le respect de l'environnement, l'expression des avantages comparatifs des bassins les plus compétitifs. A l'instar de ce qui avait été opéré dans les années quatre-vingt-dix, notamment avec les mesures d'accompagnement de la réforme de la PAC de 1992, le futur visage de la « France laitière » sera largement conditionné par les choix ou les non-choix qui seront réalisés pour gérer le prochain défi démographique qui s'annonce : du fait des installations massives au début des années quatre-vingt-dix, une part importante des producteurs laitiers devrait arrêter leur carrière dans les années qui suivront la suppression prévue des quotas. Quelle politique des structures et de l'installation les pouvoirs publics et les acteurs de la filière souhaiteront-ils privilégier? Quelles évolutions dans le mode de gestion des contrats laitiers? Quelles coordinations entre l'amont et l'aval dans les processus décisionnels ? Les réponses apportées à ces questions sont particulièrement stratégiques au regard de la configuration future du secteur laitier français.

\section{Conclusion}

Face à une demande mondiale croissante en produits laitiers, et en dépit d'une moindre intervention des pouvoirs publics dans la régulation du marché (Dedieu et Courleux 2009, Kroll 2010b), le secteur laitier français dispose de nombreux atouts pour entrevoir l'avenir. Avec un coût moyen de production plus compétitif que dans les pays européens du sud où le climat est moins favorable à la production fourragère, une amélioration sensible de sa balance commerciale au fil des ans, la présence d'entreprises de premier plan dans les classements internationaux, de fortes disponibilités foncières (du moins par rapport à certains pays du nord où, de surcroît, les niveaux d'intensification sont déjà records) et une diversité exceptionnelle de ses systèmes productifs, il n'est pas illusoire de croire dans les chances de la France. Le principal défi pour les acteurs français de cette filière sera de gérer, dans un cadre concurrentiel nouveau, la diversité des territoires et des exploitations. Plus exactement, il conviendra de trouver collectivement les moyens de faire de la diversité du secteur un atout. Si elle est parfois considérée comme un obstacle à une certaine forme de rationalisation économique (avec les processus connexes de concentration, 
de spécialisation et d'intensification), elle est aussi source de nombreuses richesses : une forte segmentation des produits laitiers qui stimule le niveau de consommation ; une répartition des risques climatiques et économiques (résilience globale) ; une contribution à la diversité paysagère et à la biodiversité ; une participation aux emplois et à la création de valeur ajoutée dans des zones rurales parfois désertées par le secteur industriel.

Tout en intégrant la question du respect des normes environnementales (question importante dans certaines zones de l'Ouest du fait de la coexistence de différentes productions animales), la France est sûrement l'un des pays européens dont le potentiel de développement de la production laitière est, à long terme, le plus important. Cette affirmation ne doit cependant pas conduire à sous-estimer la concurrence sérieuse qui existe avec plusieurs autres Etats membres de l'UE. En Allemagne, le potentiel de développement de la production laitière dépendra essentiellement de la compétitivité des entreprises sur les marchés tiers et des équilibres futurs à trouver dans l'utilisation du foncier entre les productions animales, les productions végétales et la production d'énergie (Kroll et al 2010a, Mottet et Perrot 2011). Aux PaysBas, une croissance soutenue de la production laitière semble désormais plus difficile à envisager du fait de la forte pression foncière et des exigences environnementales (You et al 2010). Au Danemark, où la productivité du travail atteint des records, la baisse récente du prix du foncier et le taux très élevé d'endettement des exploitations induisent une fragilité du système actuel (Institut de l'Elevage 2012d). En Irlande, pays où les coûts de production sont les plus avantageux de l'UE, les pouvoirs publics entendent favoriser un développement rapide de la production laitière $(+50 \%$ d'ici 2020), quitte à ce que celui-ci se fasse au détriment d'autres productions animales (Irish Ministry for Agriculture, Fisheries and Food 2011). Au RoyaumeUni, où les réorganisations spatiales ont été fortes, les perspectives de développement sont plus difficiles à présager, tant les dynamiques récentes ont laissé place à un recul de la production et à un niveau faible d'investissement dans les exploitations (Mosnier et Wieck 2012). $\mathrm{Si}$, au cours de la période récente, les nouveaux Etats membres situés à l'Est de l'UE (dont notamment la Pologne) n'ont pas été capables de réaliser leur quota, l'expression du potentiel productif dépendra surtout de l'évolution de la structuration des entreprises et des conditions d'accès aux fínancements nécessaires à la modernisation.

Avec les quotas laitiers, la concurrence entre les Etats membres de l'UE n'était que partielle dans la mesure où chacun d'eux disposait d'une protection de leurs volumes au travers des quantités globales garanties. A compter de 2015, les jeux concurrentiels intra-communautaires s'accentueront, les pays les plus dynamiques ou conquérants chercheront alors sûrement à profiter d'un marché devenu plus ouvert. Les stratégies déployées par les grandes entreprises, notamment les coopératives du nord de l'UE, seront déterminantes sur l'évolution des équilibres entre l'offre et la demande de produits laitiers. Dans l'hypothèse non négligeable où l'instauration de la contractualisation s'acheminerait par une collecte de lait dépassant, au moins tempo- rairement, les capacités globales d'écoulement sur le marché, une baisse du prix du lait payé au producteur est à craindre. Sachant que les coûts de production augmentent du fait de la pression qui s'exerce sur les ressources (énergie, engrais, soja...), cette tension sur le prix du lait accentuerait certainement le mouvement engagé de restructuration des exploitations. Pour les producteurs de lait, il résulte de cette anticipation que la recherche d'une optimisation des coûts de production est une stratégie qui s'impose non seulement pour générer du revenu, mais également pour bénéficier des opportunités de croissance ; les transformateurs auront, en effet, un intérêt stratégique à ce que les futurs volumes libérés (suite au départ en retraite des fournisseurs aînés) soient alloués au bénéfice des producteurs et des territoires les plus compétitifs.

L'avenir à long terme des différentes catégories d'exploitations laitières françaises dépendra, en outre, de l'évolution des rapports de force sur les affectations foncières (équilibre entre les productions végétales et animales, montée en puissance des normes environnementales...). La capacité des industriels de la transformation à gagner des parts de marché au niveau communautaire et, surtout, international sera déterminante quant aux volumes globaux de production. Enfin, les décisions qui seront prises dans le cadre de la future PAC, tant pour atténuer les effets de la volatilité des prix (outils de gestion du risque, réserve de crise...) que pour mieux répartir les aides directes, joueront un rôle majeur.

\section{Références}

Barthélémy D., David J., 1999. L'agriculture européenne et les droits à produire. Les interprétations nationales de la PAC. INRA Edition, Paris, France, 434p.

Bazin G., 1999. La politique de la montagne. Rapport d'évaluation. Documentation française, 819 p.

Beguin E., Roussel P., 2006. Les grandes exploitations laitières en France : état des lieux, fonctionnement, performances techniques et économiques. Renc. Rech. Rum., 13, 353-356.

Ben Arfa N., 2011. Changements structurels et dynamiques spatiales des exploitations laitières. Thèse de doctorat en sciences économiques, 199 p.

Boinon J.P., 2012. Les politiques foncières agricoles en France depuis 1945. Economie et statistique, $\mathrm{n}^{\circ} 444-445,19-37$.

Bouamra-Mechemache Z., Jongeneel R., Réquillart V., 2009. Impact of a gradual increase in milk quotas on the EU dairy sector. Eur. Rev. Agric. Econ., 35, 461-491.
Bour-Poitrinal E., Tosi J.C., 2011. Situation de la filière laitière du Massif Central : perspectives d'avenir. Rapport du CGAAER, 65p.

Boussard J.M., 2010. Pourquoi l'instabilité est-elle une caractéristique structurelle des marchés agricoles. Econ. Rurale, 320, 69-83.

Butault J.P., Hairy D., Perraud D., 1984. Crise laitière et quotas : remarques sur la régulation communautaire du marché du lait. Econ. Rurale, 163, 63-71.

Charroin T., Veysset P., Devienne S., Fromont J.L., Palazon R., Ferrand M., 2012. Productivité du travail et économie en élevage d'herbivores : définition des concepts, analyse et enjeux. In : Numéro spécial, Travail en élevage. Hostiou N., Dedieu B., Baumont R. (Eds). INRA Prod. Anim., 25, 193-210.

Chatellier V., 2010. La PAC et ses mécanismes actuels et futurs de régulation des marchés agricoles. Notes et études socio-économiques, $n^{\circ} 34,7-35$.
Chatellier V., 2011. Price volatility, market regulation and risk management: challenges for the future of the CAP. Int. Agric. Policy, 1, 33-50.

Chatellier V., Delattre F., 2003. La production laitière dans les montagnes françaises : une dynamique particulière pour les Alpes du Nord. INRA Prod. Anim., 16, 61-76.

Chatellier V., Dupraz P., 2011. Politiques et dynamique des systèmes de production : comment concilier défi alimentaire, compétitivité et environnement? Agron. Env. Soc., 1, 105115 .

Chatellier V., Guyomard H., 2012. Les propositions législatives de réforme de la PAC (octobre 2011) : premiers éléments d'analyse. INRA Sci. Soc., n ${ }^{\circ}, 8 \mathrm{p}$.

Chatellier V., Pflimlin A., Perrot C., 2008. La production laitière dans les régions de l'arc atlantique européen. INRA Prod. Anim., 21, 427-440. 
Chatellier V., Perrot C., Pflimlin A., 2009. Evolution structurelle et économique des exploitations laitières du nord de l'Union européenne de 1990 à 2005. Fourrages, 197, 25-46.

CNIEL, 2012. L'économie laitière en chiffres, $176 \mathrm{p}$.

Commission des comptes de l'agriculture de la Nation (CCAN), 2012. Les comptes prévisionnels par catégories d'exploitations pour 2012. Note de synthèse de la session du 12 décembre, $14 \mathrm{p}$.

Commission européenne, 2010. Règlement du Parlement européen et du Conseil portant modification du règlement $(\mathrm{CE}) \mathrm{n}^{\circ} 1234 / 2007$ du Conseil en ce qui concerne les relations contractuelles dans le secteur du lait et des produits laitiers, 19p.

Commission européenne, 2011a. Proposition de règlement du Parlement européen et du Conseil portant sur l'organisation commune des marchés des produits agricoles, $235 \mathrm{p}$.

Commission européenne, 2011b. Proposition de règlement du Parlement européen et du Conseil établissant les règles relatives aux paiements directs en faveur des agriculteurs, $79 \mathrm{p}$.

Commission européenne, 2012a. Prospects for agricultural markets and income in the EU 2012-2022. Report, 92 p.

Commission européenne, 2012b. EU dairy farms report 2011 based on FADN. Report DGAGRI, $136 \mathrm{p}$.

Dedieu M.S. Courleux F., 2009. Les enjeux de la régulation du secteur laitier. Note d'analyse du Centre d'études et de prospective du ministère en charge de l'agriculture, $\mathrm{n}^{\circ} 11,4 \mathrm{p}$.

Dervillé M., 2012. Territorialisation du secteur laitier et régimes de la concurrence : le cas des montagnes françaises et de leur adaptation à l'après quota. Thèse de doctorat, AgroParis Tech, Paris, France, 540p.

Dervillé M., Vandenbroucke P., Bazin G., 2012. Suppression des quotas et nouvelles formes de régulation de l'économie laitière : les conditions patrimoniales du maintien de la production laitière en montagne. Revue de la régulation, $12,22 \mathrm{p}$.

Dufour A., Giraud C., 2012. Le travail dans les exploitations d'élevage laitier est-il toujours conjugal ? In : Numéro spécial, Travail en élevage. Hostiou N., Dedieu B., Baumont R. (Eds). INRA Prod. Anim., 25, 169-180.

FAO, 2011. Price volatility in food and agricultural markets: policy responses? Report, $60 \mathrm{p}$.

FAPRI, 2011. World agricultural outlook, report, $320 \mathrm{p}$.

FranceAgriMer, 2010. La transformation laitière française : évolutions 2002-2008. Rapport, $27 \mathrm{p}$.

FranceAgriMer, 2012. Évolution et perspectives des utilisations de matières grasses et protéiques d'origine laitière par les industries agro-alimentaires dans 1'Union européenne, rapport, $146 \mathrm{p}$.

Gaigné C., 2012. Organisation des filières animales et environnement : vingt ans après la directive nitrates. INRA Prod. Anim., 25, 375 388 .

Garambois N., Devienne S., 2012. Les systèmes herbagers économes. Une alternative de développement agricole pour l'élevage bovin laitier dans le Bocage vendéen ? Econ. Rurale, 330-331, 56-72.

Gardebroek C., Turi K.N., Wijnands J.H.M., 2010. Growth dynamics of dairy processing firms in the European Union. Agric. Econ., 41, 285-291.

Gohin A., 2012. Pour faire face à la volatilité des marchés : les mécanismes de 1'OCM unique et les instruments de gestion des risques dans la nouvelle PAC. Note for European Parliament, 73p.

Gouel C., 2012. Agricultural price instability: a survey of competing explanations and remedies. J. Econ. Surveys, 26, 129-156.

Gouin D.M., 2005. La performance économique comparée des systèmes de régulation du secteur laitier, une analyse internationale. Notes et études économiques, 24, 99-133.

Guyomard H., Mahé L.P., 1993. Théorie de la production en présence de rationnements L'exemple des quotas laitiers dans la CEE. Rev. Econ., 1, 71-93.

Hairy D., Perraud D., Foulouze I., 1983. Prix du lait et systèmes de production : à propos de quelques alternatives de politique laitière. Econ. Rurale, 153, 3-13.

Institut de l'Elevage, 2007. Productivité et rémunération du travail dans les exploitations laitières du nord de l'UE. Le dossier Economie de l'Elevage, 364, 64p.

Institut de 1'Elevage, 2009a. Le lait dans les montagnes européennes. Un symbole menacé. Le dossier Economie de l'Elevage, 390, 76p.

Institut de l'Elevage, 2009b. France laitière 2015 : vers une accentuation des contrastes régionaux. Le dossier Economie de l'Elevage, 391, 72p.

Institut de l'Elevage, 2009c. La filière laitière en Espagne : une production intensive et dépendante. Le dossier Economie de l'Elevage, 394, $68 \mathrm{p}$

Institut de l'Elevage, 2010a. La filière laitière aux Pays-Bas : un dynamisme bridé ? Le dossier Economie de l'Elevage, 403, 64p.

Institut de 1'Elevage, 2010b. La filière laitière en Nouvelle-Zélande : une furieuse volonté de croissance. Le dossier Economie de l'Elevage, 404, 58p.

Institut de l'Elevage, 2011. Le lait après 2015. Comment les transformateurs comptent gérer l'offre. Le dossier Economie de l'Elevage, 418 , $48 \mathrm{p}$.

Institut de 1'Elevage, 2012a. Marchés mondiaux des produits laitiers en 2011 : anticyclone prolongé. Le dossier Economie de l'Elevage, 421, 63p.

Institut de 1'Elevage, 2012b. L'année économique laitière 2011 - Perspectives 2012. Le dossier Economie de l'Elevage, 423, 72p.

Institut de 1'Elevage, 2012c. Les Allemagnes laitières : voies divergentes et avenirs contrastés. Le dossier Economie de l'Elevage, 426, $31 \mathrm{p}$.

Institut de l'Elevage, 2012d. Les modèles laitiers des pays du Nord de l'UE à l'épreuve de la volatilité. Le dossier Economie de l'Elevage, 428, 71p.

International Dairy Federation, 2010. The world dairy situation. Bulletin, $n^{\circ} 446,207$ p.

Irish Ministry for Agriculture, Fisheries and Food, 2011. Food harvest 2020: a vision for agri-food and fisheries, report, 57p.
Jamet J.P., 2011. Crises alimentaires et marchés agricoles. Futuribles, 371, 33-46.

Jeanneaux P., Calois J.M, Wouts C., 2009. Durabilité d'un compromis territorial dans un contexte de pression compétitive accrue. Le cas de la filière AOC Comté. Rev. Econ. Reg. Urbaine, 1, 179-202.

Kroll J.C., Trouvé A., Deruaz M., 2010a. Sortie des quotas laitiers : état des lieux et perspectives en Europe. Rapport du CESEAR, UMR 1041 INRA - Agrosup Dijon, France, $57 \mathrm{p}$.

Kroll J.C., Trouvé A., Deruaz M., 2010b. Quelle perspective de régulation après la sortie des quotas? Faut-il encore une politique laitière européenne ? Rapport du CESEAR, UMR 1041 INRA - Agrosup Dijon, France, 42p.

Laisney C., 2011. L'évolution de l'alimentation en France : panorama des tendances lourdes. Futuribles, 371, 5-20.

Le Tollec O., 2012. Les produits laitiers fabriqués en agriculture biologique en 2010 . Agreste Primeur, 280, 4p.

LEI, 2011. Evaluation of CAP measures applied to the dairy sector. Report for DGAGRI (Directorate-General for Agriculture and Rural Development), 336p.

Lelyon B., Chatellier V., Daniel K., 2011. Decoupling and prices: determinant of dairy farmers' choices? Rev. Agric. Env. Studies, 92, 47-68.

Lelyon B., Chatellier V., Daniel K., 2012. Fin des quotas, contractualisation et stratégies productives : enseignements d'une modélisation bioéconomique. INRA Prod. Anim., 25 67-76.

MAAPRAT, 2010. Décret n²010-1753 du 30 décembre 2010 pris à l'initiative du Ministère de l'Agriculture, de l'Alimentation, de la Pêche, de la Ruralité et de l'Aménagement du Territoire pour l'application de l'article L. 63124 du code rural et de la pêche maritime dans le secteur laitier, $2 \mathrm{p}$.

MAAPRAT, 2011. Décret n²011-260 du Ministère de l'Agriculture, de l'Alimentation, de la Pêche, de la Ruralité et de l'Aménagement du Territoire du 10 mars 2011 portan création des conférences de bassin laitier. Journal officiel de la République Française, $3 \mathrm{p}$.

Ministère de l'agriculture, de l'agroalimentaire et de la fôret, (MAAF) 2012. Panorama des industries agroalimentaires, 62p.

Mosnier C., Wieck C., 2012. Dynamiques régionales de la production laitière: France, Allemagne, Royaume-Uni. Econ. Rurale, 332, 132-146.

Mottet A., Perrot C., 2011. Quelles distorsions de concurrence entre les filières bovines françaises et allemandes ? Renc. Rech. Rum., $18,281-284$

Mougin B., Allier D., Putot E., Seguin J.J., Stollsteiner P., Schroetter J.M., 2008. Bassins versants Bretons en contentieux européen : typologie et modélisation de l'évolution des concentrations en nitrates. Rapport final BRGM, $128 \mathrm{p}$.

Mundler P., 2010. Les dimensions territoriales de la restructuration laitière. Géographie, Econ., Soc., 12, 161-180.

OCDE-FAO, 2012. Perspectives agricoles de l'OCDE et de la FAO 2011-2020. Rapport, $306 \mathrm{p}$. 
Perrot C., 2010. Projection du nombre d'exploitations bovines laitières ou allaitantes françaises : une approche par modélisation démographique intégrant des effets territoriaux. Renc. Rech. Rum., 17, 211-214.

Perrot C., Mottet A., You G., 2011. Les modèles laitiers européens du nord de l'UE à l'épreuve de la volatilité. Renc. Rech. Rum., 18, 317-320.

Perrot C., Caillaud D., Chambaut H., 2012. Économies d'échelle et économies de gamme en production laitière : analyse technico-économique et environnementale des exploitations de polyculture-élevage françaises. Renc. Rech. Rum., 19, 33-36.

Peyraud J.L., Dupraz P., Samson E., Le Gall A., Delaby L., 2010. Produire du lait en maximisant le pâturage pour concilier performances économiques et environnementales. Renc. Rech. Rum., 17, 17-24.

Peyraud J.L., Cellier P., Donnars C. Réchauchère O., 2012. Les flux d'azote liés aux élevages, réduire les pertes, rétablir les équilibres. Expertise scientifique collective, synthèse du rapport, INRA, $68 \mathrm{p}$.

Pflimlin A., 2010. Europe laitière : valoriser tous les territoires pour construire l'avenir. Editions La France Agricole, 314p.

Pflimlin A., Faverdin P., Béranger C., 2009. Un demi-siècle d'évolution de l'élevage bovin : bilan et perspectives. Fourrages, 200, 429-464

Pointereau P., 2010. Les systèmes agricoles à haute valeur naturelle en France métropolitaine. Courrier de l'environnement de l'INRA, 59, 3-18.

Prost M., 1986. Modalités de gestion des quotas laitiers français : premier bilan et perspectives. Econ. Rurale, 172, 22-28.

Rio Y., 2012. Interprofessions et contractualisation : la régulation des marchés au sein des filières. In : Demeter 2012, Paris, France.

Rouault P., 2010. Analyse comparée de la compétitivité des industries agroalimentaires françaises par rapport à leurs concurrentes européennes. Rapport de la délégation interministérielle aux industries agroalimentaires et à l'agro-industrie, $147 \mathrm{p}$

Roullaud E., 2010. La grève européenne du lait de 2009 : réorganisation des forces syndicales sur fond de forte dérégulation du secteur. Agir-Pour, 12, 111-116.

Sénat, 1992. Les conditions d'application et les conséquences de la réglementation communautaire applicable à la filière laitière. Rapport du Sénat, 391, 241p.

Tacken G.M.L., 2009. Competitiveness of the EU dairy industry. LEI Report, 100p.

You G., Chaumet J.M., Brocard V., 2010. Potentiel laitier néerlandais : quelle production en 2020 ? Renc. Rech. Rum., 17, 203-206.

\section{Résumé}

Face à la suppression programmée des quotas laitiers en 2015, la filière laitière française traverse actuellement une période charnière de son histoire où se mêlent doutes et espoirs. La baisse rapide du nombre d'exploitations laitières (au rythme de $5 \%$ par an sur la précédente décennie), la volatilité accrue des prix, les implications environnementales négatives de l'intensification, la concurrence croissante de certains pays limitrophes (dont l'Allemagne) font douter les acteurs de la filière laitière française quant aux stratégies à déployer pour préparer efficacement l'avenir. Le secteur laitier français dispose néanmoins de nombreux atouts pour rebondir : une consommation élevée de produits laitiers par habitant et par an soutenue par une exceptionnelle variété de produits transformés ; une grande diversité de modèles techniques issue d'une adaptation historique des exploitations aux conditions du milieu naturel (relief, climat, potentiel agronomique) ; un potentiel de développement de la production du fait de la faible densité de population dans de nombreuses zones d'élevage, de l'abondance des surfaces fourragères et des substitutions envisageables entre productions ; une amélioration des connaissances scientifiques et des savoir-faire technologiques dans les entreprises; la présence de firmes leaders à l'international et une volonté des pouvoirs publics d'encourager la construction de nouvelles relations contractuelles entre producteurs et industriels, de manière à gérer l'offre en l'absence de quotas laitiers. A la veille de la suppression des quotas laitiers, l'ambition de cet article est, d'une part, de proposer une analyse de la situation économique actuelle de la filière laitière française (forces, faiblesses, diversité de modèles) et, d'autre part, de s'interroger sur les conditions de la mise en œuvre du système de contractualisation.

\section{Abstract}

\section{The French dairy sector at a crossroads: achievements and prospects}

Given the planned abolition of milk quotas in $\mathbf{2 0 1 5}$, the French dairy sector is going through a crucial period in its history, mingling doubts and hopes. The rapid decline in the number of dairy farms (at $5 \%$ per year over the previous decade), the increased price volatility, the negative environmental implications of the intensification, the increasing competition from neighbouring countries (including Germany) have cast doubt on the French players as to the strategies to be deployed to effectively prepare the future. The French dairy sector has nevertheless many assets that will help it rebound: a high level of consumption of dairy products per capita per year (also due to an exceptional diversity of processed products); a wide variety of technical models, with a historical adaptation of farms to natural conditions (climate, agronomic potential...); a high potential of production development due to a low population density in many rural areas, the abundance of available forage areas and possible substitutions between agricultural productions; some improvements in scientific knowledge and technological know-how in enterprises; some French firms are leaders at the international level; a government commitment in favour of new contractual relationships between producers and firms in order to manage supply without the milk quota system. On the eve of the abolition of milk quotas, the aim of this paper was first to propose an analysis of the current economic situation of the French dairy sector (strengths, weaknesses, diversity of models) and, second, to examine the conditions of the implementation of the contractualisation system.

CHATELLIER V., LELYON B., PERROT C., YOU G., 2013. Le secteur laitier français à la croisée des chemins. In : Numéro spécial, La vache et le lait. Faverdin P., Leroux C., Baumont R. (Eds). INRA Prod. Anim., 26, 2, 77-100. 